\title{
Hypoxia regulates TRAIL sensitivity of colorectal cancer cells through mitochondrial autophagy
}

\author{
Gertrud Knoll ${ }^{1}$, Sebastian Bittner ${ }^{1}$, Maria Kurz ${ }^{1}$, Jonathan Jantsch ${ }^{1}$, Martin \\ Ehrenschwender ${ }^{1}$ \\ ${ }^{1}$ Institute of Clinical Microbiology and Hygiene, University Hospital Regensburg, 93053 Regensburg, Germany \\ Correspondence to: Martin Ehrenschwender, e-mail: martin.ehrenschwender@ukr.de \\ Keywords: TRAIL, SMAC mimetic, death receptor, hypoxia
}

Received: December 22, 2015 Accepted: April 24, $2016 \quad$ Published: May 6, 2016

\section{ABSTRACT}

The capacity of tumor necrosis factor-related apoptosis-inducing ligand (TRAIL) to selectively induce cell death in malignant cells triggered numerous attempts for therapeutic exploitation. In clinical trials, however, TRAIL did not live up to the expectations, as tumors exhibit high rates of TRAIL resistance in vivo. Response to anti-cancer therapy is determined not only by cancer cell intrinsic factors (e.g. oncogenic mutations), but also modulated by extrinsic factors such as the hypoxic tumor microenvironment.

Here, we address the effect of hypoxia on pro-apoptotic TRAIL signaling in colorectal cancer cells. We show that oxygen levels modulate susceptibility to TRAIL-induced cell death, which is severely impaired under hypoxia $\left(0.5 \% \mathrm{O}_{2}\right)$. Mechanistically, this is attributable to hypoxia-induced mitochondrial autophagy. Loss of mitochondria under hypoxia restricts the availability of mitochondria-derived pro-apoptotic molecules such as second mitochondria-derived activator of caspase (SMAC), thereby disrupting amplification of the apoptotic signal emanating from the TRAIL death receptors and efficiently blocking cell death in type-II cells. Moreover, we identify strategies to overcome TRAIL resistance in low oxygen environments. Counteracting hypoxia-induced loss of endogenous SMAC by exogenous substitution of SMAC mimetics fully restores TRAIL sensitivity in colorectal cancer cells. Alternatively, enforcing a mitochondria-independent type-I mode of cell death by targeting the type-II phenotype gatekeeper X-linked inhibitor of apoptosis protein (XIAP) is equally effective.

Together, our results indicate that tumor hypoxia impairs TRAIL efficacy but this limitation can be overcome by combining TRAIL with SMAC mimetics or XIAPtargeting drugs. Our findings may help to exploit the potential of TRAIL in cancer therapy.

\section{INTRODUCTION}

Among the tumor necrosis factor (TNF) ligands, TNF-related apoptosis-inducing ligand (TRAIL) is unique due to its capacity to selectively induce cell death in tumor cells [1]. TRAIL binding to TRAIL receptor 1 (TRAIL-R1) or TRAIL-R2 triggers assembly of a death-inducing signaling complex (DISC). This platform allows stepwise caspase- 8 activation and initiates a cascade of proteolytic cleavage events that culminate in caspase- 3 activation, finally triggering the execution phase of apoptosis. In so-called type-I cells, caspase-8-mediated cleavage of caspase- 3 is followed by robust autocatalytic caspase- 3 processing and efficient cell death induction. In type-II cells, however, $\mathrm{X}$-linked inhibitor of apoptosis protein (XIAP) stalls caspase-3 maturation an intermediate step and has to be overridden by a mitochondria-derived amplification of the death signal. In this scenario, caspase- 8 cleavage of the BH3-interacting domain death agonist (Bid) to tBid [2] activates $\mathrm{Bcl} 2$-associated $\mathrm{X}$ protein (Bax) and Bcl2-antagonist/killer (Bak). Bax and Bak form a pore 
complex in the outer mitochondrial membrane and unleash pro-apoptotic factors such as cytochrome c, HtrA2 and second mitochondria-derived activator of caspase (SMAC) [3]. Together with apoptotic-proteaseactivating factor 1 (Apaf-1), cytochrome c forms the 'apoptosome', a molecular scaffold for caspase-9 activation, which in turn boosts downstream effector caspase activation. SMAC and HtrA2 act synergistically by neutralizing cytosolic inhibitors of apoptosis proteins (IAPs), especially XIAP [4, 5].

Soon after its discovery, TRAIL emerged as a promising anti-cancer agent with encouraging results in pre-clinical studies. Disappointingly, the therapeutic benefit of TRAIL in clinical trials is to date rather limited [6]. The reasons for TRAIL's sobering clinical performance are incompletely understood. We and others previously showed that cancer-cell intrinsic factors, such as the oncogenic PIK3CA H1047R mutation conferred high-level TRAIL resistance in colorectal cancer cells [7, 8]. Additionally, extrinsic factors, such as the tumor microenvironment affect the response to anti-cancer therapies [9]. In solid malignancies, fast proliferation can outgrow the supply of nutrients and oxygen provided by the malformed tumor vasculature. Hypoxia is common in human cancers and grants stabilization of hypoxiainducible factor $1 \alpha(\operatorname{HIF} 1 \alpha)$. This transcription factor ensures cell survival through adaptive changes in cell metabolism (reviewed in [10]). Notably, HIF1 $\alpha$ has also been implicated in carcinogenesis and metastasis of colorectal cancer [11] and overexpression is associated with poor prognosis [12].

Here, we show that hypoxia induced TRAIL resistance in colorectal cancer cells. Oxygen deprivation reduced the levels of mitochondria-derived pro-apoptotic SMAC and HtrA2 molecules by hypoxiainduced mitophagy, thereby disrupting mitochondriadependent amplification of the TRAIL-triggered death signal and blocking apoptosis in type-II cells. Inhibition of hypoxia-induced mitophagy or replacement of endogenous SMAC with exogenously added SMAC mimetics fully restored TRAIL cytotoxicity under hypoxic conditions. Additionally, switching typeII cells to a type-I mode of cell death by targeting the type-II phenotype gatekeeper XIAP rendered mitochondrial death signal amplification dispensable and allowed full-blown TRAIL-induced apoptosis under hypoxic conditions. Together, we identified hypoxia as an extrinsic modulator of TRAIL susceptibility in colorectal cancer cells. Therapeutically, our results indicate that combinatorial treatments with TRAIL and SMAC mimetics or XIAP-targeting drugs can overcome hypoxia-induced TRAIL resistance and may offer a promising strategy to exploit the potential of TRAIL in cancer therapy.

\section{RESULTS}

\section{Hypoxia reduces TRAIL-induced cell death in colorectal cancer cells}

Hypoxia $\left(0.5 \% \mathrm{O}_{2}\right)$ significantly attenuated TRAILinduced cell death in the colorectal cancer cell lines HCT116 (Figure 1A), HCT-8 (Figure 1C) and DLD1 (Figure 1D) compared to normoxia (ambient air, 21\% $\mathrm{O}_{2}$ ) in MTT- (Figure 1A, 1C, 1D) and crystal violet-based viability assays (Figure 1B). Expectedly, TRAIL-induced loss of viability under normoxic conditions was associated with activation of caspase-3, a prototypic effector caspase in apoptosis (Figure 1E). TRAIL-triggered translocation of phosphatidylserine (PS) to the outer leaflet of the plasma membrane, another hallmark of ongoing apoptosis, was prominent under normoxia but tremendously reduced under hypoxia (Figure 1F). We next investigated whether hypoxia selectively impairs TRAIL death receptor-mediated cytotoxic effects or also influences pro-apoptotic signaling of other death receptors such as CD95. Indeed, hypoxia attenuated cell death in CD95L-treated HCT-8 (Figure 1G) and HCT116 cells (Figure 1H), thereby pointing to a more general role of oxygen levels in modulating death receptorassociated pro-apoptotic signaling pathways. Hypoxiamediated TRAIL resistance was dependent on the persistent absence of oxygen and rapidly vanished when normoxic conditions were restored (Figure 1I). The attenuation of TRAIL-induced cell death visible in DLD1 cells under hypoxic conditions (black bars) was completely reversible by normoxic cultivation for additional $24 \mathrm{~h}$ (grey bars) or $48 \mathrm{~h}$ (green bars) before adding TRAIL. Additionally, the extent of hypoxia-induced TRAIL resistance correlated with the levels of available oxygen (Figure 1J). Whereas TRAILinduced cell death was strongly inhibited in the presence of $0.5 \% \mathrm{O}_{2}$ (black bars) and $5 \% \mathrm{O}_{2}$ (grey bars), oxygen levels of $7.5 \%$ (red bars) and above fully restored TRAIL cytotoxicity to normoxic levels (white bars). Notably, oxygen levels between 5 and $10 \%$ are physiologically encountered in various tissues [13]. Together, these date demonstrated that oxygen levels modulate death receptorinduced cell death in colorectal cancer cells.

\section{Hypoxia alters expression of pro- and anti-apoptotic proteins}

We next addressed the molecular mechanisms underlying hypoxia-induced TRAIL resistance in colorectal cancer cells. Using an antibody-based protein array (Figure 2A), we measured oxygen-dependent changes in the abundance of pro- and anti-apoptotic proteins in cell lysates. Hypoxia not only reduced expression levels of TRAIL-R1, TRAIL-R2 and Fasassociated death domain (FADD), but also lowered the abundance of mitochondria-derived pro-apoptotic factors 
A

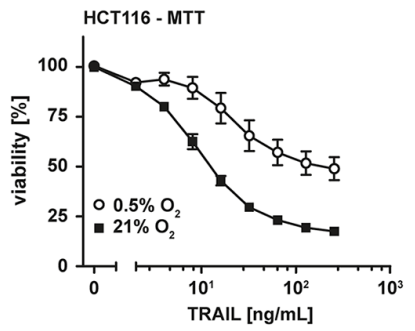

D

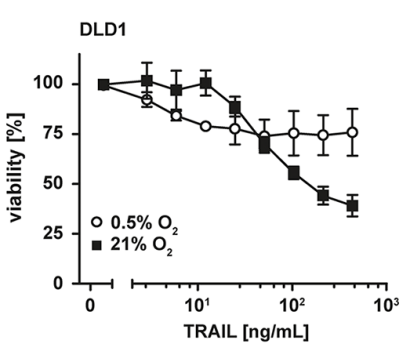

G

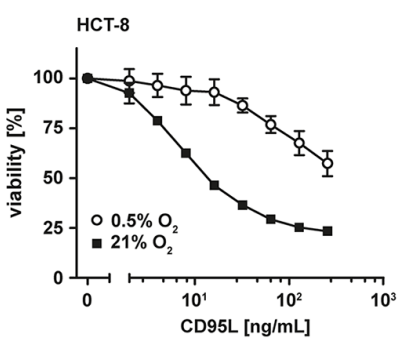

J

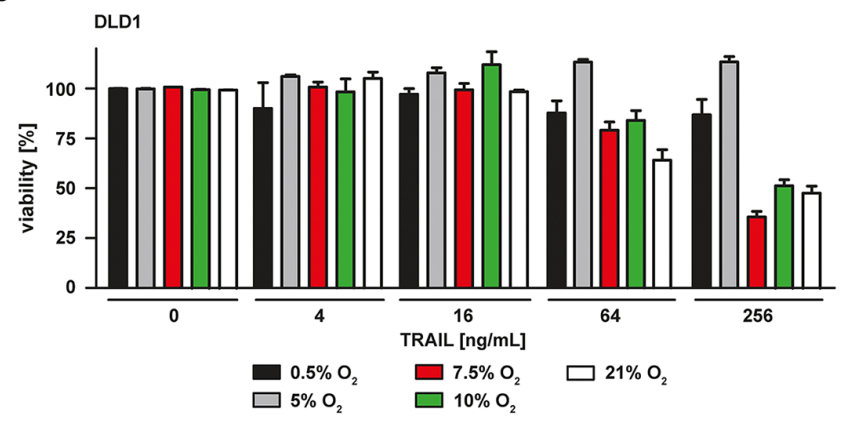

C
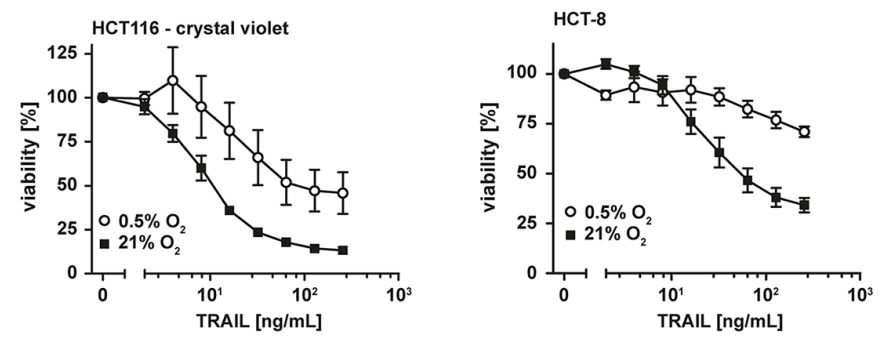

E

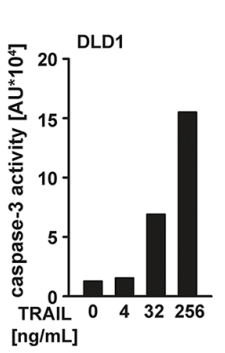

F

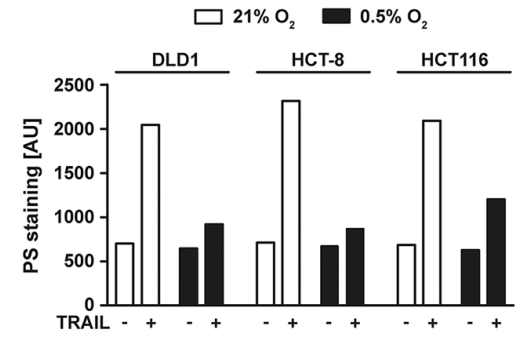

I
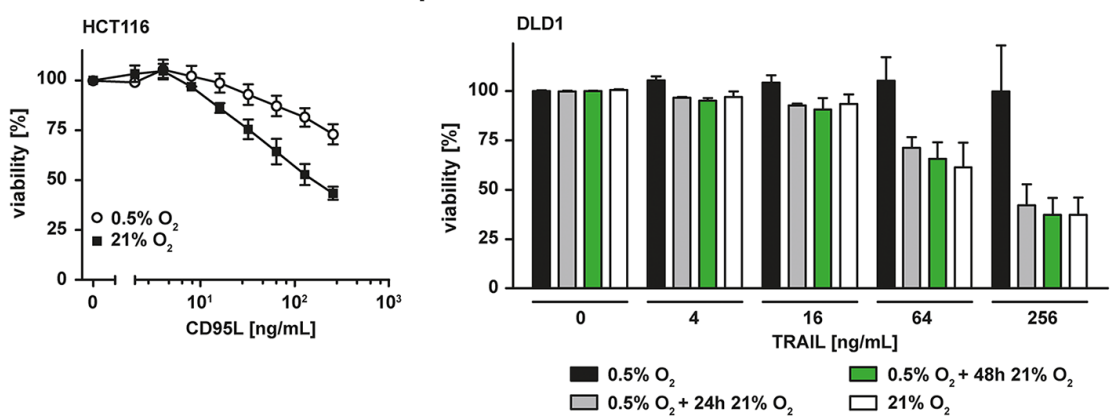

Figure 1: Hypoxia reduces TRAIL-induced cell death in colorectal cancer cells. A-D. HCT116, HCT-8 and DLD1 cells were grown under normoxic $\left(21 \% \mathrm{O}_{2}\right)$ or hypoxic $\left(0.5 \% \mathrm{O}_{2}\right)$ conditions for $18 \mathrm{~h}$. Subsequently, cells were challenged with the indicated concentrations of TRAIL for another $18 \mathrm{~h}$. Viability was measured using MTT (A, C, D) or crystal violet (B) staining. Values are means \pm SEM from three experiments. E. DLD1 cells were challenged with the indicated concentrations of TRAIL for 5 h. Caspase-3 activity was measured using the fluorogenic substrate (DEVD) $)_{2}-\mathrm{R} 110$. One representative experiment of three performed is shown. AU, arbitrary units. F. DLD1, HCT-8 and HCT116 cells were grown under normoxic $\left(21 \% \mathrm{O}_{2}\right)$ or hypoxic $\left(0.5 \% \mathrm{O}_{2}\right)$ conditions for $18 \mathrm{~h}$. Subsequently, cells were challenged with $256 \mathrm{ng} / \mathrm{mL}$ TRAIL for $3 \mathrm{~h}$ or left untreated. Translocation of phosphatidylserine to the outer leaflet of the plasma membrane was measured using a fluorogenic Annexin V derivate. One representative experiment of two performed is shown. PS, phosphatidylserine. G, H. HCT-8 and HCT116 cells were grown under normoxic $\left(21 \% \mathrm{O}_{2}\right)$ or hypoxic $\left(0.5 \% \mathrm{O}_{2}\right)$ conditions for $18 \mathrm{~h}$. Subsequently, cells were challenged with the indicated concentrations of CD95L for additional $18 \mathrm{~h}$. Cell viability was measured using MTT staining. Values are means \pm SEM from three experiments. I. DLD1 cells were grown under normoxic $\left(21 \% \mathrm{O}_{2}\right)$ or hypoxic $\left(0.5 \% \mathrm{O}_{2}\right)$ conditions for $18 \mathrm{~h}$. Hypoxia-experienced cells were subsequently split in three groups and grown in an environment containing $0.5 \% \mathrm{O}_{2}$ (black bars) for 24 $\mathrm{h}$ or $21 \% \mathrm{O}_{2}$ for $24 \mathrm{~h}$ (grey bars) or $48 \mathrm{~h}$ (green bars). Subsequently, cells were challenged with the indicated concentrations of TRAIL for $18 \mathrm{~h}$. Cell viability was measured using MTT staining. Values are means \pm SEM from three experiments. J. DLD1 cells were grown under normoxic $\left(21 \% \mathrm{O}_{2}\right)$ or various hypoxic $\left(0.5 \%-10 \% \mathrm{O}_{2}\right)$ conditions for $18 \mathrm{~h}$. Subsequently, cells were challenged with the indicated concentrations of TRAIL for another $18 \mathrm{~h}$. Viability was measured using MTT staining. Values are means \pm SEM from three experiments. 
such as HtrA2 and SMAC. Expression of caspase-3, an essential molecule in the effector phase of apoptosis, did not significantly differ in hypoxic and normoxic conditions (Figure 2A). Therefore, hypoxia most likely blocked activation of the effector phase of apoptosis rather than abolishing the effector mechanism itself. Oxygen deprivation also reduced the levels of the antiapoptotic proteins Survivin and XIAP, whereas the levels of Bcl-2, Bcl-X $\mathrm{L}_{\mathrm{L}}$, cIAP1 and cIAP2 were only minimally affected. Apparently, this reduction was not sufficient to enhance TRAIL sensitivity, as hypoxia decreased rather than increased TRAIL-induced cytotoxicity in colorectal cancer cells (Figure 1). To validate our proteome array data, we examined whether the hypoxia-induced loss of pro-apoptotic proteins functionally contributes to the attenuated TRAIL sensitivity observed in a low oxygen environment. Importantly, a mere reduction of a proapoptotic molecule in cell lysates not necessarily promotes
A

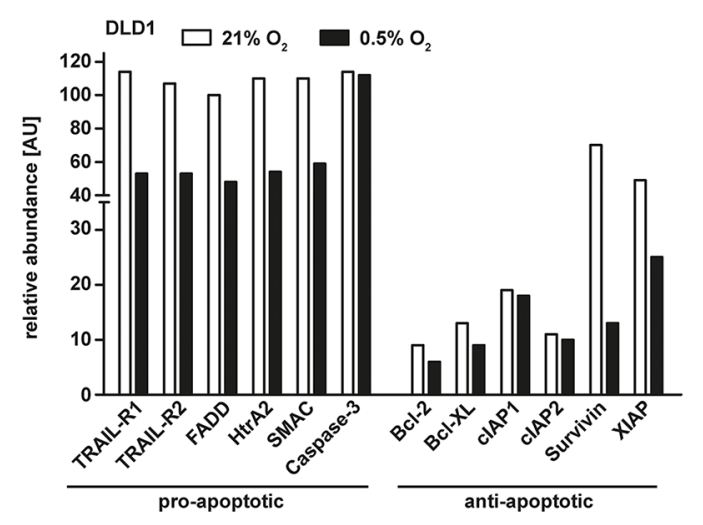

C

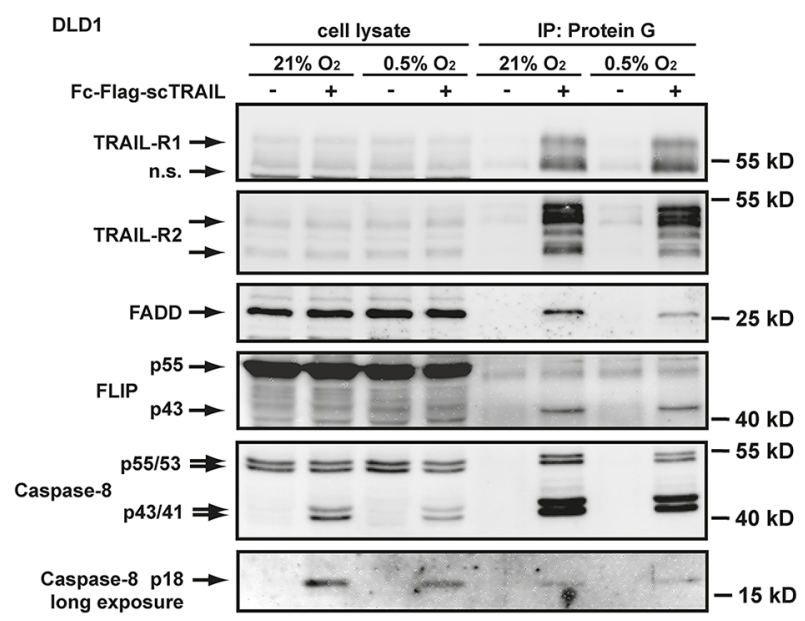

B

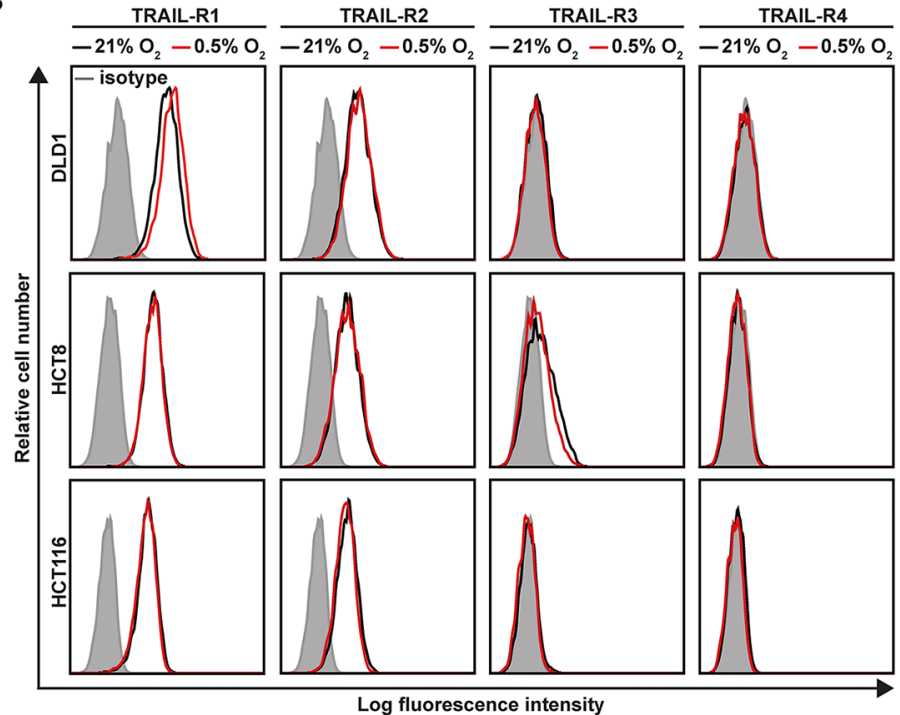

D

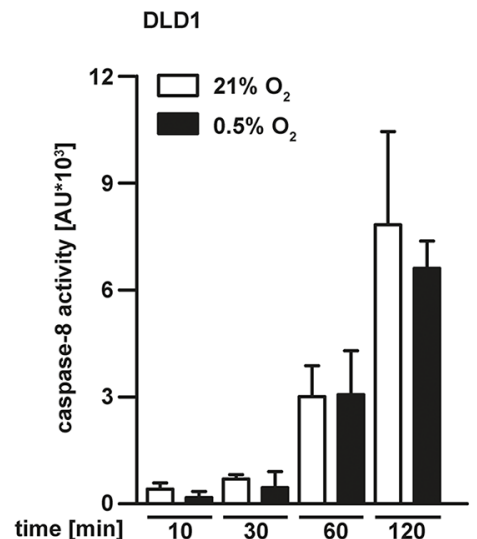

Figure 2: Hypoxia changes the expression levels of pro- and anti-apoptotic proteins but does not impair TRAIL-induced DISC formation. A. DLD1 cells were grown under normoxic $\left(21 \% \mathrm{O}_{2}\right)$ or hypoxic $\left(0.5 \% \mathrm{O}_{2}\right)$ conditions for $18 \mathrm{~h}$. Subsequently, cells were lysed and relative expression levels of the indicated proteins were measured using an antibody-based array (see Material and Methods section). Proteins were quantified using densitometry and normalized to reference spots. Data shown are representative of two experiments performed. AU, arbitrary units. B. DLD-1, HCT-8 and HCT116 cells were grown for $18 \mathrm{~h}$ under normoxic $\left(21 \% \mathrm{O}_{2}\right)$ or hypoxic $\left(0.5 \% \mathrm{O}_{2}\right)$ conditions and subsequently analyzed for TRAIL-R1, TRAIL-R2, TRAIL-R3 and TRAIL-R4 cell surface expression using flow cytometry. Data shown are representative of three experiments performed. C. TRAIL-R1/-R2 signaling complexes were induced in DLD1 cells grown for $18 \mathrm{~h}$ under normoxic $\left(21 \% \mathrm{O}_{2}\right)$ or hypoxic $\left(0.5 \% \mathrm{O}_{2}\right)$ conditions by stimulation with Fc-FLAG-scTRAIL $(1 \mu \mathrm{g} / \mathrm{mL})$ for $90 \mathrm{~min}$. Proteins associated with Fc-FLAG-scTRAIL were immunoprecipitated using protein G agarose and were analyzed together with the corresponding lysates by Western blotting for the presence of TRAIL-R1 and TRAIL-R2 and the DISC components FADD, FLIP and caspase-8. Data shown are representative of two experiments performed. D. DLD1 cells were grown for $18 \mathrm{~h}$ under normoxic $\left(21 \% \mathrm{O}_{2}\right)$ or hypoxic $(0.5 \%$ $\mathrm{O}_{2}$ ) conditions and subsequently challenged with $256 \mathrm{ng} / \mathrm{mL}$ TRAIL for the indicated periods of time. Caspase- 8 activity was measured using the fluorogenic substrate (Ac-IETD) $)_{2}$-R110. Values are means \pm SEM from three experiments. AU, arbitrary units. 
survival, as factor-specific thresholds and the subcellular location of proteins have to be considered. For example, the observed decrease in the total cellular amount of TRAIL-R1 and TRAIL-R2 under hypoxia allows no conclusion regarding the cell surface expression of the TRAIL death receptors. Ligand binding to death receptors occurs at the plasma membrane and initiates the apoptosisinducing signaling cascade, cell surface localization is therefore functionally of outstanding importance (for review see [14]). Flow cytometry revealed that the observed reduction in the total amount of TRAIL-R1 and TRAIL-R2 under hypoxic conditions did not correlate with decreased expression of these death receptors at the cell surface (Figure 2B). TRAIL-R1 and TRAIL-R2 surface expression under hypoxia was comparable to normoxia. Additionally, lowering oxygen levels to $0.5 \%$ did not affect expression levels of the decoy receptors TRAIL-R3 and TRAIL-R4. In line with these findings, immunoprecipitation experiments demonstrated that TRAIL-induced receptor signaling complex formation occurred equally effective under hypoxic or normoxic conditions (Figure 2C). Notably, we did not detect significant oxygen-dependent differences in the amount of precipitated TRAIL-R1 and TRAIL-R2. Although total cellular FADD levels were reduced under hypoxia (Figure 2A), FADD was precipitated together with TRAIL-R1 and TRAIL-R2 (Figure 2C), suggesting that the remaining amount was still sufficient to form a functional death receptor-associated signaling complex. In line with this, TRAIL-induced processing of the caspase- 8 p55/53 pro-form via the $\mathrm{p} 43 / 41$ intermediate at the DISC to the enzymatically active p18 fragment occurred roughly to the same extend under hypoxic or normoxic conditions (Figure 2C). Undisturbed TRAIL-induced caspase-8 activation under oxygen deprivation was also confirmed in caspase- 8 activity assays (Figure 2D). Together, our data indicated that the initial steps of apoptosis induction were intact and hypoxia blocked TRAIL-induced cell death downstream of receptor-ligation, DISC formation and caspase- 8 activation.

\section{Hypoxia induces loss of mitochondrial mass}

Following activation of initiator caspases at the DISC, release of mitochondria-derived apoptosispromoting proteins such as HtrA2 and SMAC are in type-II cells essential (and in type-I cells accelerative) for full-blown effector caspase activation and cell death. The reduced HtrA2 and SMAC levels under low oxygen conditions (Figure 2A) could therefore impair TRAIL-induced cell death downstream of DISC formation. Efficient release of apoptotic proteins from the intermembrane space of mitochondria depends on a stimulus-triggered increase in cytosolic $\mathrm{Ca}^{2+}$ [15]. In CD95 signaling, CD95L-induced $\mathrm{Ca}^{2+}$ efflux from the endoplasmic reticulum is important for mitochondrial permeabilization and CD95-mediated apoptosis [16,
17]. We analyzed TRAIL-induced changes in cytosolic $\mathrm{Ca}^{2+}$ under hypoxic and normoxic conditions (Figure 3A). In both scenarios, TRAIL was comparably effective in augmenting cytosolic $\mathrm{Ca}^{2+}$, suggesting that oxygendependent differences in $\mathrm{Ca}^{2+}$ fluxes are unlikely to explain the lower levels of mitochondria-derived pro-apoptotic molecules under hypoxia.

Notably, a previous study demonstrated that hypoxia triggered mitochondrial autophagy as an adaptive metabolic response [18]. Staining of mitochondria in DLD1 cells grown under hypoxic conditions using the membrane potential-independent MitoTracker dye revealed a reduced staining intensity compared to normoxic controls (Figure 3B). This pointed to a hypoxiainduced decrease of mitochondrial mass. Importantly, cell proliferation was comparable under normoxic and hypoxic conditions (Figure 3C), excluding simple differences in cell number as causative for the decrease in mitochondrial mass under low oxygen. Additionally, enhanced autophagosome formation was detectable under hypoxic conditions (Figure 3D). In line with hypoxia-induced mitophagy, pharmacological blockade of autophagy using 3-methyladenine (3MA) attenuated the loss of mitochondria (Figure 3E). Moreover, 3MA overcame TRAIL resistance in hypoxic DLD1, HCT-8 and HCT116 cells (Figure 3F), thereby demonstrating the functional relevance of mitophagy for hypoxia-induced TRAIL resistance. In the absence of oxygen, HIF $1 \alpha$ ensures (tumor) cell survival by coordinating the broad metabolic reprogramming at the transcriptional level (reviewed in [10]). DLD1 cells grown under hypoxic conditions expectedly stabilized HIF1 $\alpha$ (Figure 3G). Interestingly, a recent study demonstrated a crucial role for HIF $1 \alpha$ in hypoxia-induced mitophagy [18]. Consequently, inhibiting HIF $1 \alpha$ in our experimental system should decrease hypoxia-induced mitophagy and enhance TRAIL-induced cell death. Indeed, blocking HIF1 $\alpha$ using the pharmacological inhibitor Bay87-2243 [19] (Figure $3 \mathrm{G})$ attenuated or even abolished oxygen-dependent differences in TRAIL sensitivity (Figures $3 \mathrm{H}$ and 3I). In sum, we demonstrated that oxygen deprivation reduced TRAIL sensitivity of colorectal cancer cells via hypoxiainduced mitophagy.

\section{SMAC mimetics overcome hypoxia-induced TRAIL resistance}

The observed loss of mitochondria-derived proapoptotic proteins (such as SMAC) under hypoxic conditions (Figure 2A) was accompanied by a decrease in mitochondrial mass (Figure 3B) and impaired TRAIL sensitivity, suggesting that the release of apoptosis-promoting factors from mitochondria is essential for efficient propagation of the apoptotic signal. In line with this, HCT116 cells deficient for Bax (HCT116 $\mathrm{Bax}^{-/}$), a crucial player in mitochondrial permeabilization during apoptosis, exhibited high-level 
TRAIL resistance irrespective of the surrounding oxygen levels (Figure 4A). Consequently, restoring or imitating the mitochondria-mediated amplification of the apoptotic signal, e.g. with small-molecules mimicking the endogenous IAP antagonist SMAC (SMAC mimetics), could allow effective TRAIL-based treatments even in hypoxic tumor microenvironments. The SMAC mimetic BV6 efficiently reduced cellular levels of XIAP (Figure 4B) and resensitized HCT116 $\mathrm{Bax}^{-/-}$(Figure 4A), HCT116, HCT-8 and DLD1 cells grown under hypoxic conditions to TRAILand/or CD95L-induced cell death (Figure 4C and 4E-4H). Notably, enhanced cytotoxicity of TRAIL in the presence
A

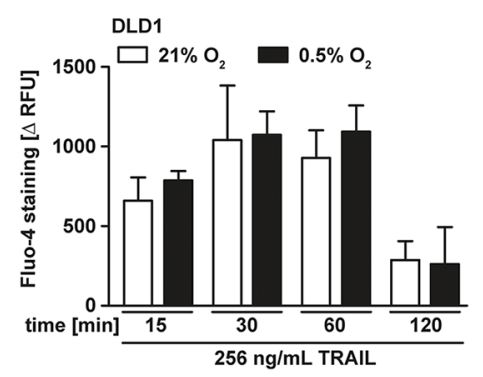

F

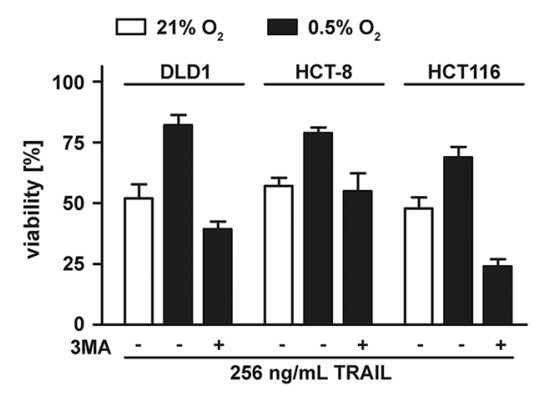

I

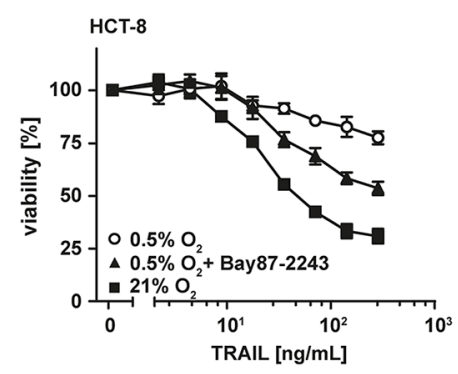

B

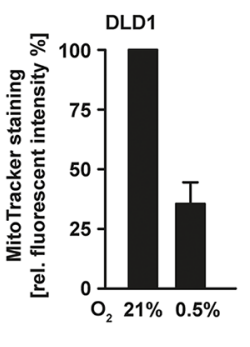

G

DLD1

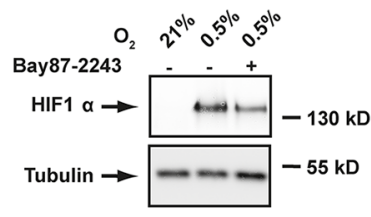

D
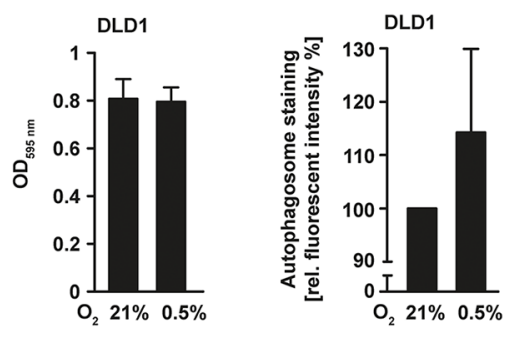

E

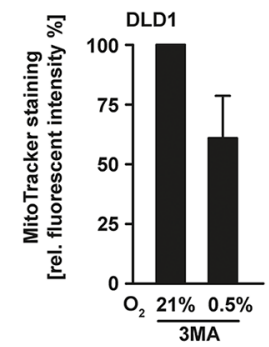

H

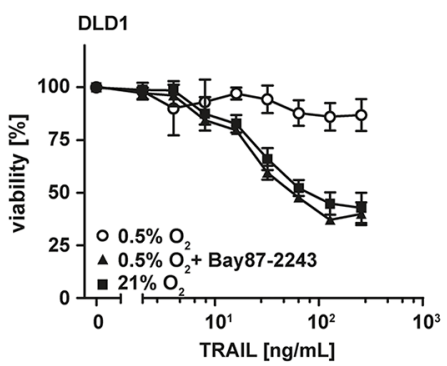

Figure 3: Hypoxia-induced mitochondrial autophagy decreases TRAIL sensitivity. A. DLD1 cells were grown under normoxic $\left(21 \% \mathrm{O}_{2}\right.$, white bars) and hypoxic $\left(0.5 \% \mathrm{O}_{2}\right.$, black bars) conditions for $18 \mathrm{~h}$ and subsequently challenged with $256 \mathrm{ng} / \mathrm{mL}$ TRAIL for the indicated periods of time. Cytosolic $\mathrm{Ca}^{2+}$ levels were measured using Fluo-4 staining and quantified in a microplate reader. To calculate TRAIL-induced $\mathrm{Ca}^{2+}$ influx $(\triangle \mathrm{RFU})$, the fluorescence intensity from untreated controls was subtracted from every condition. Values are means \pm SEM from three experiments. RFU, relative fluorescent units. B. DLD1 cells were grown as in (A) followed by staining of mitochondria using MitoTracker Green FM. Fluorescence intensity was quantified using a microplate reader and is given relative to the normoxic control. Values are means \pm SEM from three experiments. C. DLD1 cells were grown as in (A) and cell proliferation was measured using MTT staining. Values are means \pm SEM from three experiments. D. Cells were treated as in (A) followed by autophagosome staining. Fluorescence intensity was quantified using a microplate reader and is given relative to the normoxic control. Values are means \pm SEM from three experiments. E. DLD1 cells were grown as in (A) in the presence of the autophagy inhibitor 3MA (12 mM). Subsequently, mitochondria were stained using MitoTracker and fluorescence was quantified in a microplate reader. Data are given relative to the corresponding normoxic controls. Values are means \pm SEM from three experiments. F. DLD1, HCT- 8 and HCT116 cells were grown as in (A) in the presence and absence of the autophagy inhibitor 3MA (12 mM) and subsequently challenged with the TRAIL (256 ng/mL) for $18 \mathrm{~h}$. Viability was measured using MTT staining. Values are means \pm SEM from three experiments. G. DLD1 cells were grown for 18 $\mathrm{h}$ under normoxic $\left(21 \% \mathrm{O}_{2}\right)$ and hypoxic $\left(0.5 \% \mathrm{O}_{2}\right)$ conditions in the presence and absence of the HIF $1 \alpha$ inhibitor Bay $87-2243(50 \mu \mathrm{M})$. HIF1 $\alpha$ levels were analyzed by Western blotting, tubulin served as loading control. H, I. DLD1 and HCT-8 cells were grown as in (A) in the presence and absence of the HIF1 $\alpha$ inhibitor Bay87-2243 $(25 \mu \mathrm{M})$ and subsequently challenged with the indicated concentrations of TRAIL for $18 \mathrm{~h}$. Viability was measured using MTT staining. Values are means \pm SEM from three experiments. 
A

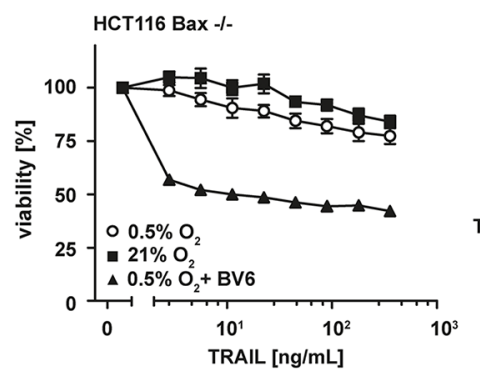

C

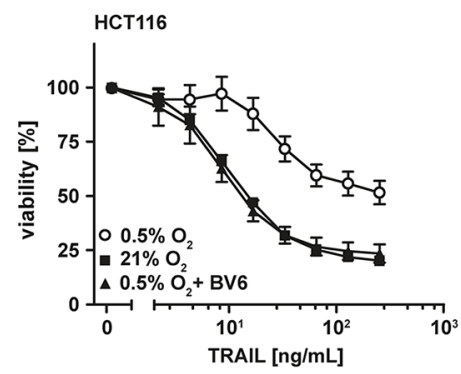

F

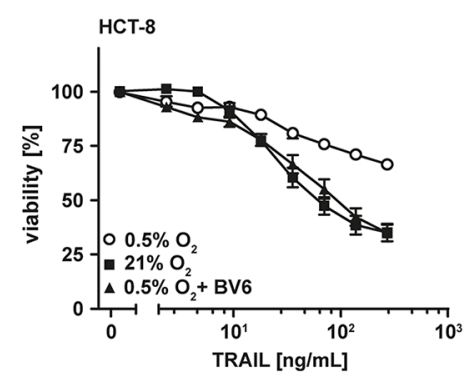

J

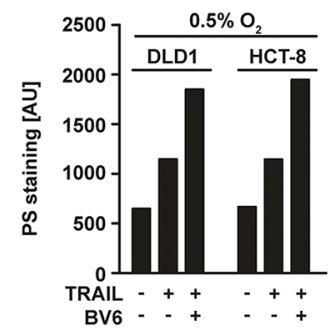

B

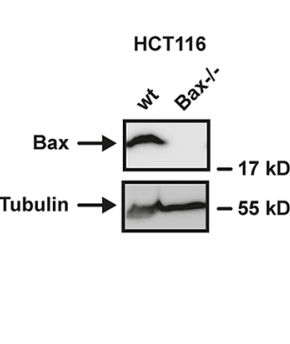

D

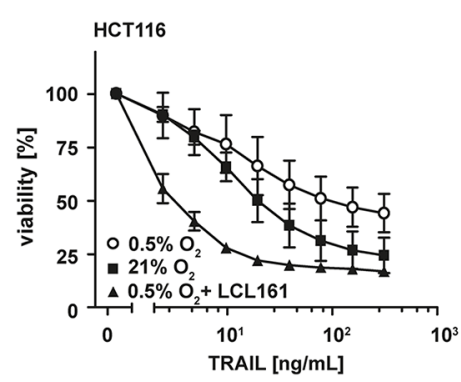

H
E

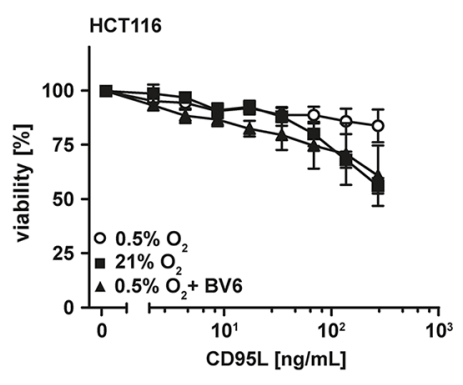

G

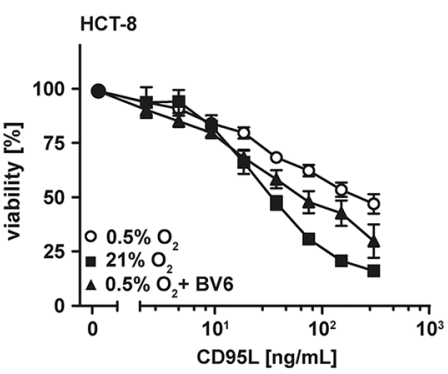

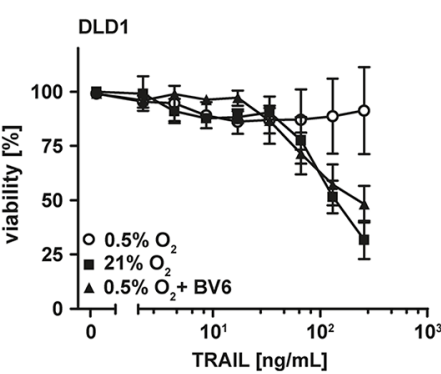
$0.5 \% \mathrm{O}_{2}$
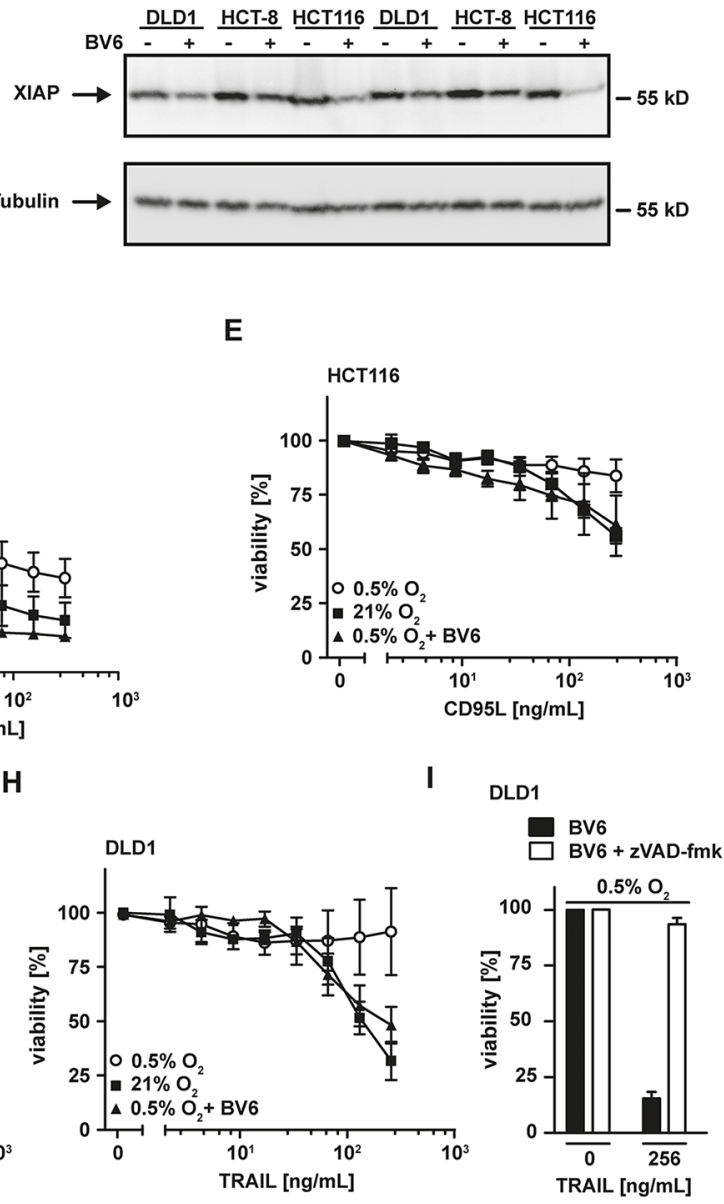

Figure 4: SMAC-mimetics overcome hypoxia-induced apoptosis resistance. A. left panel: HCT116 Bax ${ }^{-/}$cells were grown under normoxic $\left(21 \% \mathrm{O}_{2}\right)$ and hypoxic $\left(0.5 \% \mathrm{O}_{2}\right)$ conditions for $18 \mathrm{~h}$ in the presence and absence of BV6 $(6.25 \mu \mathrm{M})$. Subsequently, cells were challenged with the indicated concentrations of TRAIL for another $18 \mathrm{~h}$. Viability was measured using MTT staining. Values are means \pm SEM from three experiments. Right panel: Bax expression in HCT116 wildtype and HCT116 Bax ${ }^{-/}$cells was assessed by Western blotting. Tubulin served as loading control. B. HCT116, HCT-8 and DLD1 cells were grown as in (A) in the presence and absence of the SMAC mimetic BV6 (HCT116: $6.25 \mu \mathrm{M}$; HCT8: 6.25 $\mu \mathrm{M}$; DLD1: $25 \mu \mathrm{M})$. XIAP levels were analyzed by Western blotting, tubulin served as loading control. C-H. HCT116, HCT-8 and DLD1 cells were grown as in (A) in the presence and absence of the SMAC mimetics BV6 (HCT116: $6.25 \mu \mathrm{M}$; HCT8: $6.25 \mu \mathrm{M}$; DLD1: $25 \mu \mathrm{M}$ ) or LCL161 $(25 \mu \mathrm{M})$. Thereafter, cells were stimulated with the indicated concentrations of TRAIL or CD95L for $18 \mathrm{~h}$ and cell viability was measured using MTT staining. Values are means \pm SEM from three experiments. I. DLD1 cells were grown under hypoxic conditions $\left(0.5 \% \mathrm{O}_{2}\right)$ for $18 \mathrm{~h}$ in the presence of BV6 $(25 \mu \mathrm{M}$, black bars) or BV6 + zVAD-fmk $(100 \mu \mathrm{M}$, white bars). Subsequently, cells were treated with the indicated concentrations of TRAIL for $18 \mathrm{~h}$. Cell viability was measured using MTT staining. Values are means \pm SEM from three experiments. J. DLD1 and HCT- 8 cells were grown under hypoxic $\left(0.5 \% \mathrm{O}_{2}\right)$ conditions for $18 \mathrm{~h}$ in the presence and absence of BV6 (DLD1: $25 \mu \mathrm{M}$; HCT-8: $6.25 \mu \mathrm{M}$ ). Subsequently, cells were challenged with the indicated concentrations of TRAIL for $3 \mathrm{~h}$. Translocation of phosphatidylserine to the outer leaflet of the plasma membrane was measured using a fluorogenic Annexin V derivate. One representative experiment of two performed is shown. PS, phosphatidylserine. 
of SMAC mimetics was not attributable to BV6-induced autocrine TNF secretion, as TNF was not detectable in the supernatant of BV6-treated cells (data not shown). LCL161, a SMAC mimetic that already entered phase II clinical trials (reviewed in [20]), also increased TRAIL-induced cell death under low oxygen levels (Figure 4D). The pan-caspase inhibitor zVAD-fmk completely abrogated TRAIL-induced cell death in BV6-treated DLD1 cells under hypoxia (Figure 4I) and combinatorial treatment with BV6 and TRAIL strongly increased PS exposure at the outer leaflet of the plasma membrane (Figure $4 \mathrm{~J}$ ), together pointing to ongoing apoptotic rather than necroptotic cell death. Collectively, our data highlighted that SMAC mimetics efficiently overcame hypoxia-induced TRAIL resistance in colorectal cancer cells.

\section{XIAP is critical for hypoxia-induced TRAIL resistance}

Apparently, hypoxia-induced mitophagy disrupted the required mitochondrial amplification of pro-apoptotic TRAIL signaling, thereby effectively blocking apoptosis in type-II cells. The anti-apoptotic protein XIAP acts as a gatekeeper of the type-II phenotype [21, 22]. We and others demonstrated that targeting XIAP is capable to convert type-II to type-I cells [21, 23, 24]. Our data indicated intact TRAIL-induced DISC formation under hypoxic conditions (Figure 2C). Consequently, enforcing a mitochondria-independent type-I mode of cell death should restore TRAIL cytotoxicity in hypoxia. In line with this hypothesis, XIAP-deficient HCT116 (HCT116 $\mathrm{XIAP}^{-/-}$) cells displayed a tremendously reduced TRAIL resistance under hypoxic conditions (Figure 5A) compared to HCT116 wildtype cells (Figure 1A). Blocking Sp1mediated XIAP transcription using mithramycin-A (MithA) [25] (Figure 5B) enhanced TRAIL-induced cell death in HCT116 cells with a dysfunctional mitochondrial cell death pathway due to Bax-deficiency (Figure 5C). Moreover, MithA treatment of hypoxic HCT116 (Figures 5D and 5E), HCT-8 (Figures 5F and 5G) and DLD1 cells (Figure 5H) restored TRAIL- and CD95L-induced cell death. Inhibition of caspases using zVAD-fmk fully rescued MithA-treated DLD1 cells under hypoxia from TRAIL-induced cell death (Figure 5I) and combinatorial treatment with BV6 and TRAIL strongly increased PS exposure at the outer leaflet of the plasma membrane (Figure 5J). This argued for ongoing apoptosis in a mitochondria-independent type-I mode and we therefore next investigated the requirement for mitochondriaderived amplification of the death signal when XIAP is blocked. TRAIL-induced cleavage of the caspase- 8 substrate Bid to tBid was equally effective in DLD1 cells grown under hypoxic or normoxic conditions (Figure $6 \mathrm{~A})$, which is in line with preserved DISC formation (Figure 2C) and caspase-8 activation (Figure 2D). In lysates from isolated mitochondria, we also observed no oxygen-dependent differences in TRAIL-induced Bid/tBid translocation to the mitochondria (Figure 6B), pointing to a resistance mechanism downstream of these initial steps of the mitochondrial amplification loop. Notably, hypoxia reduced the amount of the mitochondrial protein TOM20 (Figure 6B) and the total cellular content of cytochrome c (Figure 6C), which conforms to the previously observed hypoxia-induced loss of mitochondrial mass (Figure 3B). These observations support our hypothesis that hypoxia-induced mitophagy and concomitant reduction of mitochondria-derived pro-apoptotic molecules is the key mechanism for TRAIL-resistance granted during hypoxia. Restoring TRAIL-induced apoptosis using XIAP-targeting drugs did not depend on mitochondrial amplification of the death signal, as robust caspase-3 activation in HCT116 $\mathrm{Bax}^{-/}$cells was observable upon challenge with TRAIL+BV6 or TRAIL+MithA even though release of mitochondria-derived pro-apoptotic molecules was defective (Figure 6D). Likewise, hypoxia-induced mitophagy reduced TRAIL-triggered caspase-3 activation in HCT116 cells to levels of HCT116 $\mathrm{Bax}^{-/}$cells. Again, BV6 and MithA fully restored TRAIL-induced caspase-3 activation under hypoxic conditions. In sum, these data suggested that XIAP was essential for hypoxia-induced TRAIL resistance and targeting this druggable molecule rendered mitochondrial amplification of the apoptotic stimulus superfluous.

\section{Combinations of TRAIL with SMAC mimetics or mithramycin-A are also effective in colorectal cancer cells displaying apoptosis resistance under ample oxygen}

Tumor cells may not depend on hypoxia to develop TRAIL resistance, but already exhibit this trait under normoxic conditions. Therefore, we questioned whether combinatorial treatment with TRAIL plus SMAC mimetics or MithA was also efficient in colorectal cancer cells with TRAIL resistance under normoxia. In combination with the SMAC mimetics BV6 or LCL161, TRAIL robustly induced cell death in HT29 (Figures 7A and 7B) and SW480 cells (Figures 7D and 7E). Comparable to SMAC mimetics, MithA also sensitized HT29 and SW480 cells to TRAIL-induced apoptosis (Figures 7C and 7F). Noteworthy, in the absence of these compounds the apoptotic response to TRAIL in both cell lines was at best moderate.

\section{Hypoxia reduces efficacy of apoptosis-inducing anti-cancer drugs in colorectal cancer cells}

We finally investigated whether apoptosis induction of anti-cancer drugs such as cis-platin (cisPt) and staurosporine (STS) was also impaired under low oxygen conditions. Compared to normoxia, we observed reduced cytotoxicity of both cisPt and STS in hypoxic DLD1, 
A

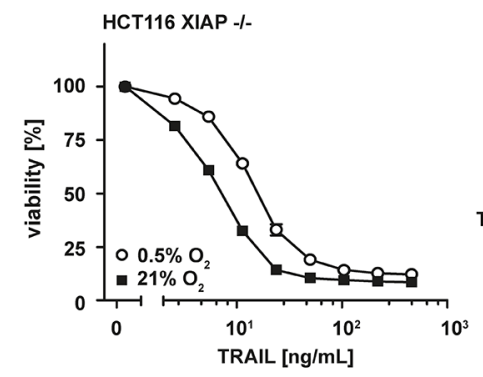

C

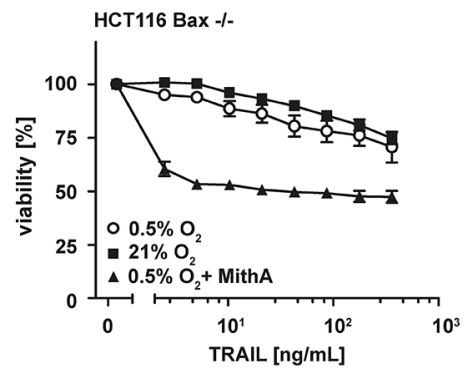

$\mathbf{F}$

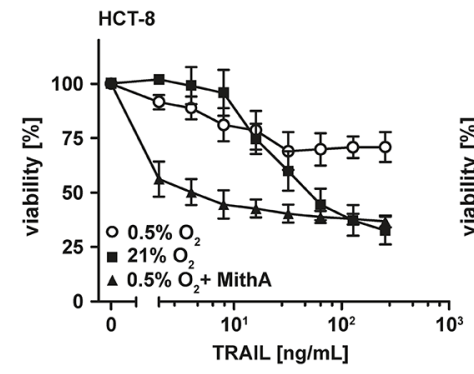

J

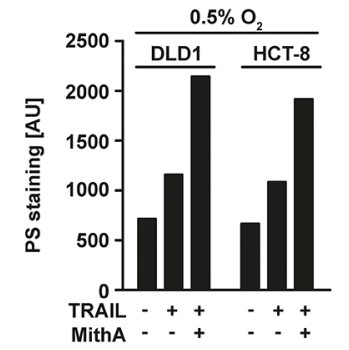

B

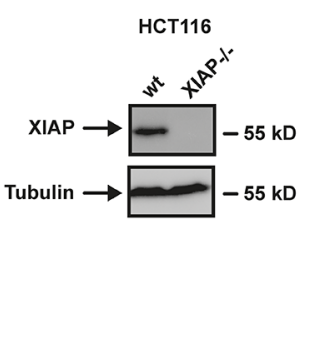

D
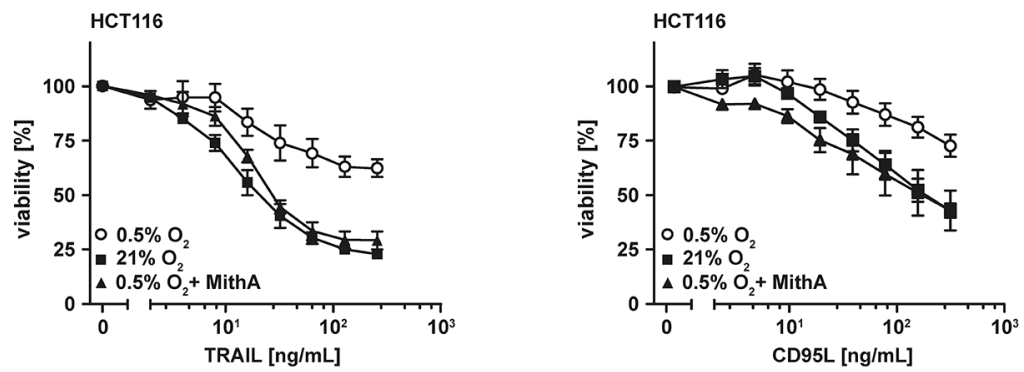

I DLD1

H
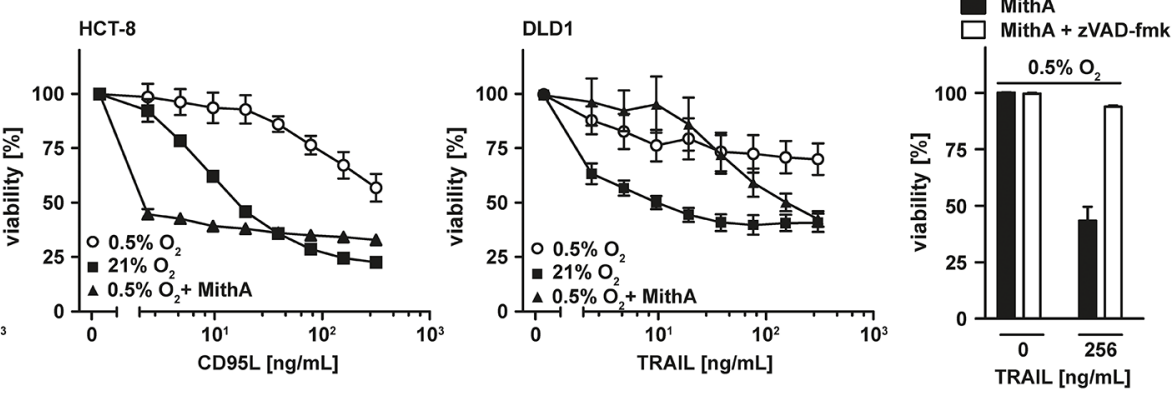

Figure 5: XIAP is critical for hypoxia-induced TRAIL resistance. A. left panel: HCT116 XIAP $/$ - cells were grown under normoxic $\left(21 \% \mathrm{O}_{2}\right)$ and hypoxic $\left(0.5 \% \mathrm{O}_{2}\right)$ conditions for $18 \mathrm{~h}$. Following stimulation with the indicated concentrations of TRAIL for another $18 \mathrm{~h}$, viability was measured using MTT staining. Values are means \pm SEM from three experiments. Right panel: XIAP expression in HCT116 wildtype and HCT116 XIAP ${ }^{-/}$cells was assessed by Western blotting. Tubulin served as loading control. B. HCT116, HCT8 and DLD1 cells were grown as in (A) in the presence and absence of mithramycin-A (HCT-8 and DLD1: 125 nM; HCT116: 10 nM). XIAP levels were analyzed by Western blotting, tubulin served as loading control. MithA, mithramycin-A. C-H. HCT116 Bax ${ }^{-/}$, HCT116, HCT-8 and DLD1 cells were grown as in (A) in the presence and absence of mithramycin-A (HCT116 Bax ${ }^{-/}$, HCT-8 and DLD1: 125 nM; HCT116: $10 \mathrm{nM}$ ) Thereafter, cells were stimulated with the indicated concentrations of TRAIL or CD95L for $18 \mathrm{~h}$ and cell viability was measured using MTT staining. Values are means \pm SEM from three experiments. I. DLD1 cells were grown under hypoxic conditions $\left(0.5 \% \mathrm{O}_{2}\right)$ for $18 \mathrm{~h}$ in the presence of MithA (125 nM, black bars) or MithA and zVAD-fmk (100 $\mu \mathrm{M}$, white bars). Subsequently, cells were treated with the indicated concentrations of TRAIL for $18 \mathrm{~h}$. Cell viability was measured using MTT staining. Values are means \pm SEM from three experiments. J. DLD1 and HCT-8 cells were grown under hypoxic $\left(0.5 \% \mathrm{O}_{2}\right)$ conditions for $18 \mathrm{~h}$ in the presence and absence of mithramycin-A (125 nM). Subsequently, cells were challenged with the indicated concentrations of TRAIL for $3 \mathrm{~h}$. Translocation of phosphatidylserine to the outer leaflet of the plasma membrane was measured using a fluorogenic Annexin V derivate. One representative experiment of two performed is shown. PS, phosphatidylserine. 
HCT-8 and HCT116 cells (Figure 8A-8C). Again, BV6 enhanced the cisPt- and STS-triggered cell death induction under low oxygen conditions (Figure 8D).

Summing up, our data demonstrate that colorectal cancer cells can acquire TRAIL resistance in a hypoxic environment. Mechanistically, this can be traced back to hypoxia-induced mitophagy. The later not only disables mitochondria-dependent amplification of death receptorderived apoptotic signals (and thereby efficiently blocks cell death in type-II cells), but also impairs effectivity of other apoptosis-inducing anti-cancer drugs. Antagonizing anti-apoptotic IAP proteins using SMAC mimetics or enforcing a mitochondria-independent type-I mode of cell death by targeting XIAP restored sensitivity towards apoptosis regardless of oxygen levels and could also be exploited therapeutically.

\section{DISCUSSION}

Hypoxia regulates numerous genes associated with tumor vascularization, invasion, drug resistance and metastasis (reviewed in [11]). The effects of hypoxia on TRAIL-induced cell death remain to date controversial. Initial observations indicated that hypoxia does not impair TRAIL-triggered cell death [26], but subsequent reports [27-30] and our current study found hypoxia-induced TRAIL resistance in a variety of cell lines (Figure 1). Notably, hypoxia not only increased resistance to TRAILbut also to CD95L-, cisPt- and STS-induced cell death (Figure $1 \mathrm{G}$ and $1 \mathrm{H}$, Figure 8). Oxygen deprivation may therefore act as a more general protective mechanism against apoptosis induction, possibly by disturbing an essential death promoting mechanism shared among different stimuli. In line with this, our data indicated that the hypoxia-induced cell death blockade is located downstream of death receptor activation and DISC formation, because cell surface expression of TRAIL-R1 and TRAIL-R2 (Figure 2B), recruitment of DISC components (Figure 2C) and caspase- 8 activation (Figure 2D) were preserved under hypoxia. This is essentially in accordance with the previously reported intact TRAILinduced caspase- 8 and Bid cleavage in hypoxic HCT116
A

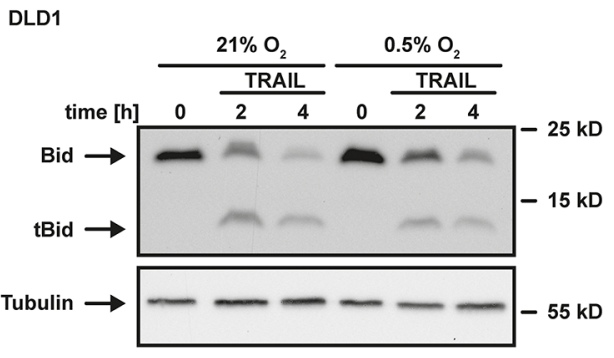

B

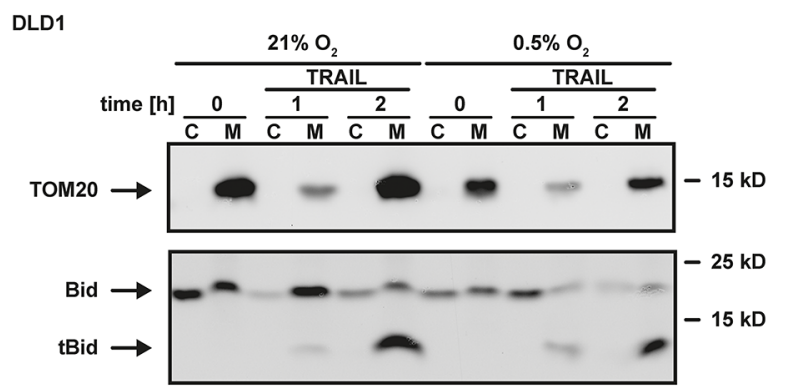

C

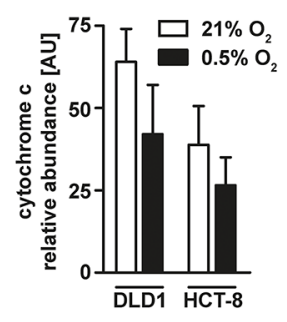

D

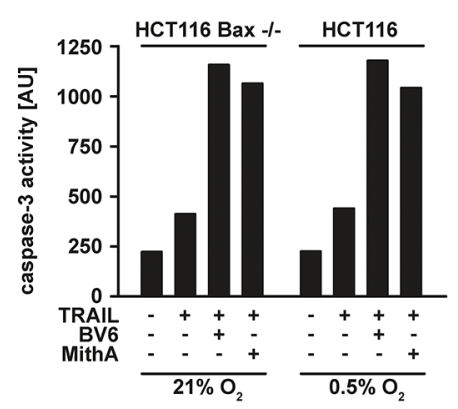

Figure 6: Hypoxia does not affect Bid cleavage and translocation to the mitochondria. A. DLD1 cells were grown under normoxic $\left(21 \% \mathrm{O}_{2}\right)$ and hypoxic $\left(0.5 \% \mathrm{O}_{2}\right)$ conditions for $18 \mathrm{~h}$. Subsequently, cells were challenged with $100 \mathrm{ng} / \mathrm{mL}$ TRAIL for the indicated periods of time. Processing of Bid into tBid was assessed by Western blotting. Tubulin served as loading control. B. Cells were grown as in (A) and challenged with $100 \mathrm{ng} / \mathrm{mL}$ TRAIL for the indicated periods of time. Subsequently, cells were harvested, lysed and separated into a cytosolic ("C") and mitochondrial ("M") fraction. Processing of Bid into tBid and mitochondrial translocation was assessed by Western blotting. Detection of TOM20 served as a mitochondrial marker protein to control sufficient fractionation of the lysates. C. DLD1 and HCT- 8 cells were grown under normoxic $\left(21 \% \mathrm{O}_{2}\right)$ or hypoxic $\left(0.5 \% \mathrm{O}_{2}\right)$ conditions for $18 \mathrm{~h}$. Subsequently, cells were lysed and relative expression levels of cytochrome $\mathrm{c}$ were measured using an antibody-based array (see Material and Methods section). Proteins were quantified using densitometry and normalized to reference spots. Data shown are means \pm SEM from two experiments. AU, arbitrary units. D. In the presence and absence of BV6 $(6.25 \mu \mathrm{M})$ or mithramycin-A (HCT116 Bax $\left.{ }^{-/:}: 125 \mathrm{nM}, \mathrm{HCT} 116: 10 \mathrm{nM}\right), \mathrm{HCT} 116 \mathrm{Bax} /$ were $^{-/}$ grown under normoxic $\left(21 \% \mathrm{O}_{2}\right)$ conditions and HCT116 cells were grown under hypoxic conditions $\left(0.5 \% \mathrm{O}_{2}\right)$ for 18 h. Subsequently, cells were challenged with TRAIL $(128 \mathrm{ng} / \mathrm{mL})$ for $4 \mathrm{~h}$. Caspase- 3 activity was measured using the fluorogenic substrate (DEVD) $)_{2}$ R110. One representative experiment of two performed is shown. AU, arbitrary units. 
$\mathrm{Bax}^{+/-}$cells, although that study did not examine death receptor expression and DISC formation [31].

The molecular mechanism that impairs TRAIL sensitivity in colorectal cancer cells under hypoxia is incompletely understood, but a pivotal role for mitochondria is emerging. Hypoxic conditions in TRAIL- treated HCT116 $\mathrm{Bax}^{+/}$reduced Bax translocation from the cytosol to the mitochondria, thereby impairing cytochrome c release, subsequent caspase- 3 activation and apoptosis induction [28, 31]. However, these studies did not assess the effects of low oxygen levels on the cellular mitochondrial mass. Notably, hypoxia is a potent inducer of
A

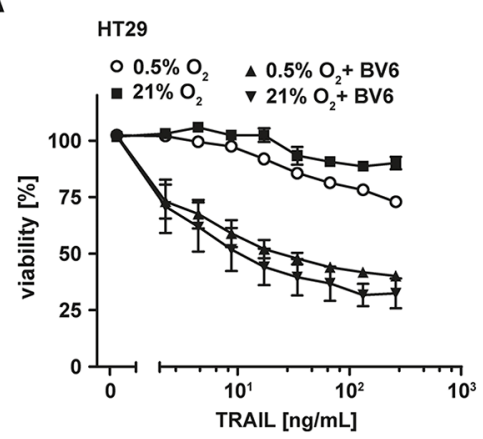

D

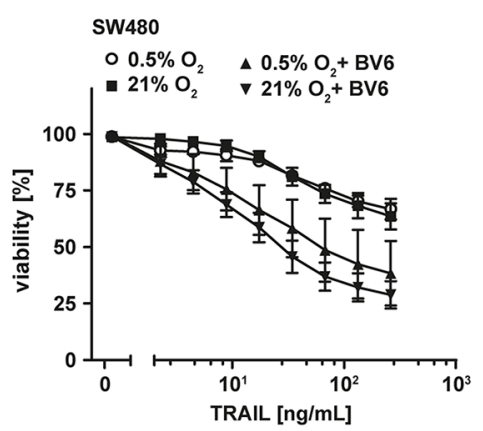

B

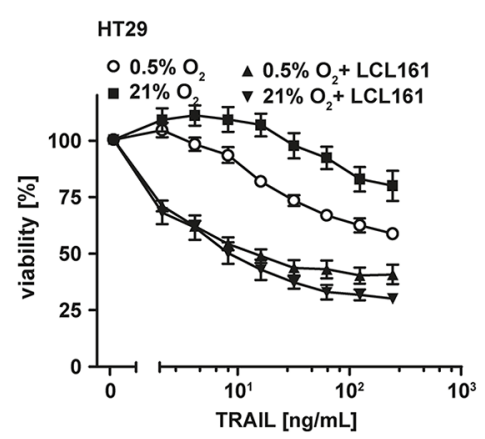

E

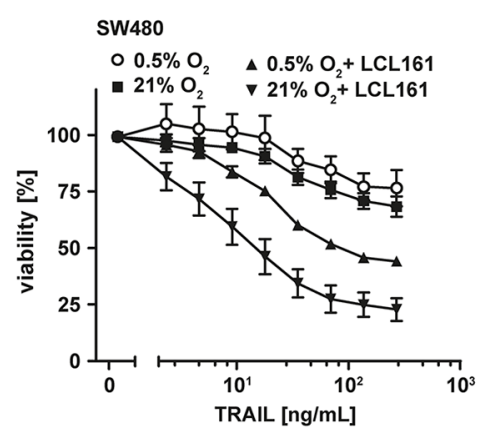

C

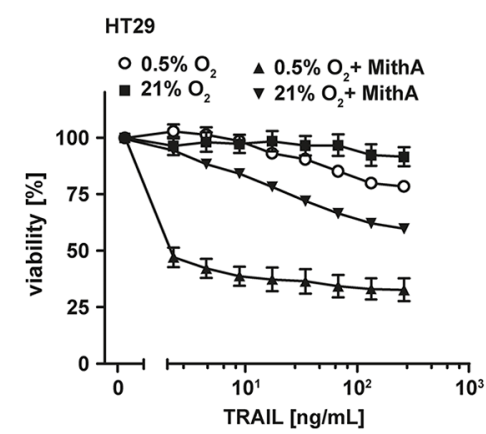

$\mathbf{F}$

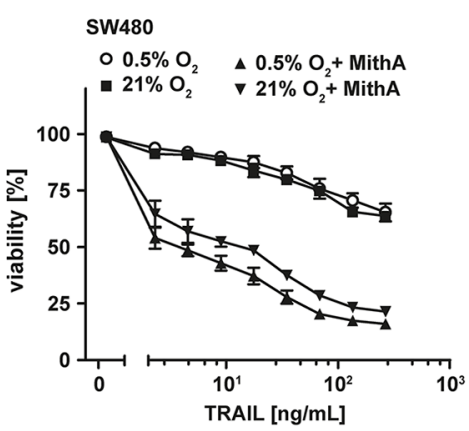

Figure 7: Combinations of TRAIL with SMAC mimetics or mithramycin-A also overcome TRAIL resistance under normoxic conditions. A-F. HT29 and SW480 cells were grown under normoxic $\left(21 \% \mathrm{O}_{2}\right)$ and hypoxic $\left(0.5 \% \mathrm{O}_{2}\right)$ conditions for 18 $\mathrm{h}$ in the presence and absence of BV6 $(6.25 \mu \mathrm{M})$ or LCL161 (HT29: $12.5 \mu \mathrm{M}$; SW480: $25 \mu \mathrm{M})$ or mithramycin-A (125 nM). Thereafter, cells were treated with the indicated concentrations of TRAIL for another $18 \mathrm{~h}$. Cell viability was measured using MTT staining. Values are means \pm SEM from three experiments. MithA, mithramycin-A.

A

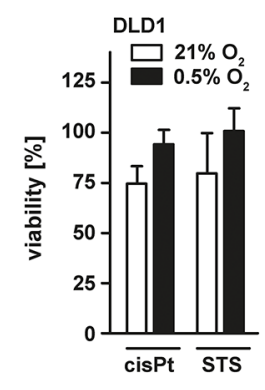

B

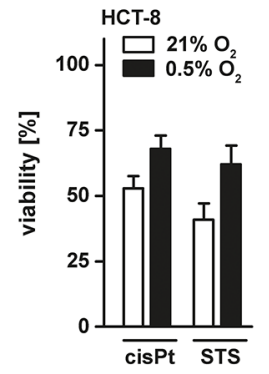

C

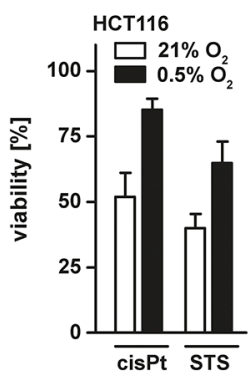

D

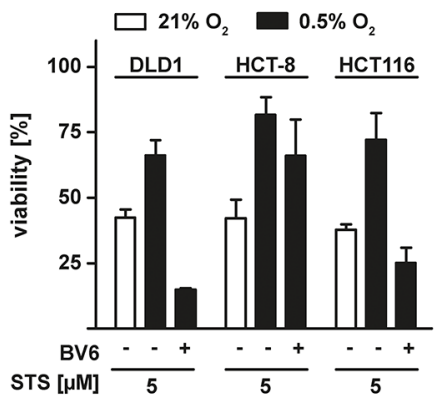

Figure 8: Hypoxia decreases sensitivity of colorectal cancer cells to apoptosis-inducing drugs. A-C. DLD1, HCT- 8 and HCT116 cells were grown under normoxic $\left(21 \% \mathrm{O}_{2}\right)$ and hypoxic $\left(0.5 \% \mathrm{O}_{2}\right)$ conditions for $18 \mathrm{~h}$. Subsequently, cells were challenged with cis-platin (cisPt, $125 \mu \mathrm{M}$ ) or staurosporine (STS, $5 \mu \mathrm{M}$ ) for another $18 \mathrm{~h}$. Cell viability was measured using MTT staining. Values are means \pm SEM from three experiments. D. DLD1, HCT-8 and HCT116 were grown under normoxic $\left(21 \% \mathrm{O}_{2}\right)$ and hypoxic $\left(0.5 \% \mathrm{O}_{2}\right)$ conditions for $18 \mathrm{~h}$ in the presence and absence of BV6 (DLD1: $25 \mu \mathrm{M}$; HCT-8 and HCT116: $6.25 \mu \mathrm{M}$ ). Subsequently, cells were challenged with STS $(5 \mu \mathrm{M})$ for another $18 \mathrm{~h}$ and cell viability was measured using MTT staining. Values are means \pm SEM from three experiments. 
mitophagy [18] and a recent study elegantly demonstrated that the mitochondrial outer-membrane protein FUNDC1 links mitochondria to the autophagic machinery [32]. This study also reported reduced cytochrome c levels in cells grown under oxygen deprivation. It is therefore tempting to speculate that TRAIL resistance could be attributable to hypoxia-induced mitophagy rather than inefficient mitochondrial translocation of the pore forming Bax/Bak complex. Assigning hypoxia-induced TRAIL resistance to mitophagy is supported by our data for the following reasons: First of all, the decrease of mitochondrial mass under low oxygen levels (Figure 3B) was associated with enhanced autophagosome formation (Figure 3D). Secondly, the autophagy inhibitor 3MA reduced the loss of mitochondria under hypoxia (Figure 3E). And finally, the autophagy inhibitor 3MA reversed TRAIL resistance in hypoxic DLD1, HCT-8 and HCT116 cells (Figure 3F).

Admittedly, blocking autophagy under hypoxia using 3MA could also modulate TRAIL susceptibility by mitochondria-independent mechanisms. At least under normoxia, TRAIL can trigger a protective autophagic response that does not involve mitochondria [33, 34]. However, hypoxia-induced mitophagy depends on HIF1 $\alpha$ [18] while TRAIL triggered autophagy does not [33]. The HIF1 $\alpha$ inhibitor Bay87-2243 [19] restored TRAIL sensitivity under hypoxia (Figures $3 \mathrm{H}$ and 3I), arguing against involvement of TRAIL-triggered protective autophagic responses in hypoxia-induced TRAIL resistance.

When apoptosis is blocked, the TRAIL death receptors and CD95 can elicit pro-inflammatory signaling pathways [35, 36] with tumor promoting activities [7]. In vivo, CD95 activation in hypoxic metastasized colorectal cancer cells enhanced proliferation and promoted a highly invasive phenotype [37]. Consequently, ensuring or restoring full-blown cell death induction is a prerequisite for therapeutic exploitation of death receptors in cancer therapy.

Our study highlights potential new strategies to overcome hypoxia-induced TRAIL resistance, either by targeting the tumor environment (oxygen levels) or by antagonizing cellular adaptions to hypoxia (loss of mitochondria). Obviously, oxygen levels determine the degree of hypoxia-granted TRAIL resistance (Figure 1J), which is reversible upon re-oxygenation (Figure 1I). The efficacy of TRAIL-based anti-cancer therapies could therefore be boosted by increasing oxygen levels in tumors. Respiratory hyperoxia diminished hypoxia in the tumor microenvironment in a mouse tumor model [38] and additionally enhanced T- and NK-cell mediated immunological anti-tumor responses [39]. However, systemic hyperoxygenation may be technically challenging in the clinical setting. Increasing efficiency of oxygen delivery instead by promoting tumor vascularization is therefore an interesting alternative. A recent study reported that increasing tumor angiogenesis improved drug delivery, reduced tumor growth as well as metastasis and extended survival [40]. Therefore, combinatorial treatment with TRAIL and drugs promoting tumor angiogenesis might constitute a reasonable therapeutic approach.

Identification of hypoxia-induced mitophagy as the molecular mechanism underlying TRAIL resistance under oxygen deprivation allowed us to additionally characterize cancer cell intrinsic therapeutic targets. Imitating mitochondria-dependent amplification of the TRAILtriggered death signal by exogenously adding SMAC mimetics (Figure $4 \mathrm{C}-4 \mathrm{H}$ ) or enforcing a mitochondriaindependent type-I mode of cell death by targeting XIAP, the gatekeeper of the type-II phenotype (Figure 5C-5H) [21, 22], boosted TRAIL- and CD95L-induced cell death. Both approaches also robustly killed colorectal cancer cells that exhibited high-level TRAIL resistance in the presence of ample oxygen (Figure 7). Moreover, BV6 restored cisPt- and STS-induced cell death under hypoxic conditions (Figure 8), altogether broadening the clinical applicability. SMAC mimetics do not exhibit an exclusive specificity for a single IAP protein and target to a varying degree cIAP1, cIAP2 and XIAP [41]. XIAP seems to hold a crucial role in hypoxia-induced TRAIL resistance, as the latter is tremendously reduced in genetically XIAPdeficient cells and when XIAP transcription is blocked (Figure 5). Additionally, XIAP is the most potent caspase inhibitor among the IAP proteins [42] and therefore in all probability responsible for the TRAIL resistant phenotype under hypoxia. However, we can not formally exclude an additional role for cIAP1 and cIAP2. Notably, hypoxia reduced the total cellular content of XIAP and other antiapoptotic molecules (Figure 2A), but apparently not below the critical threshold to allow for TRAIL sensitization in the absence of mitochondria-derived apoptotic signals (Figure 1). Although TRAIL death receptors are capable to trigger caspase-dependent apoptosis and caspase-independent necroptosis [35, 43], zVAD-fmk-mediated rescue (Figure 4I and 5I) and PS exposure on the outer leaflet of the plasma membrane pointed to apoptotic cell death (Figure $4 \mathrm{~J}$ and $5 \mathrm{~J}$ ). Killing cancer cells via apoptosis rather than necroptosis could therapeutically be desirable as the later is capable to initiate a strong inflammatory response [44].

Taken together, we identified hypoxia-induced mitophagy as a novel mechanism to regulate TRAIL sensitivity in oxygen-deprived colorectal cancer cells and characterized cancer cell intrinsic and extrinsic approaches for re-sensitization to TRAIL-based anticancer therapy (summarized in Figure 9). Therapeutically, we provide experimental evidence that combinatorial treatment strategies with TRAIL and SMAC mimetics or XIAP-targeting drugs overcome the apoptosishampering conditions imposed by the hypoxic tumor microenvironment. Our findings extend previous approaches to overcome hypoxia-induced apoptosis resistance [29, 30] and also have a broad clinical applicability in colorectal cancer cells exhibiting TRAILresistance under normoxia. 


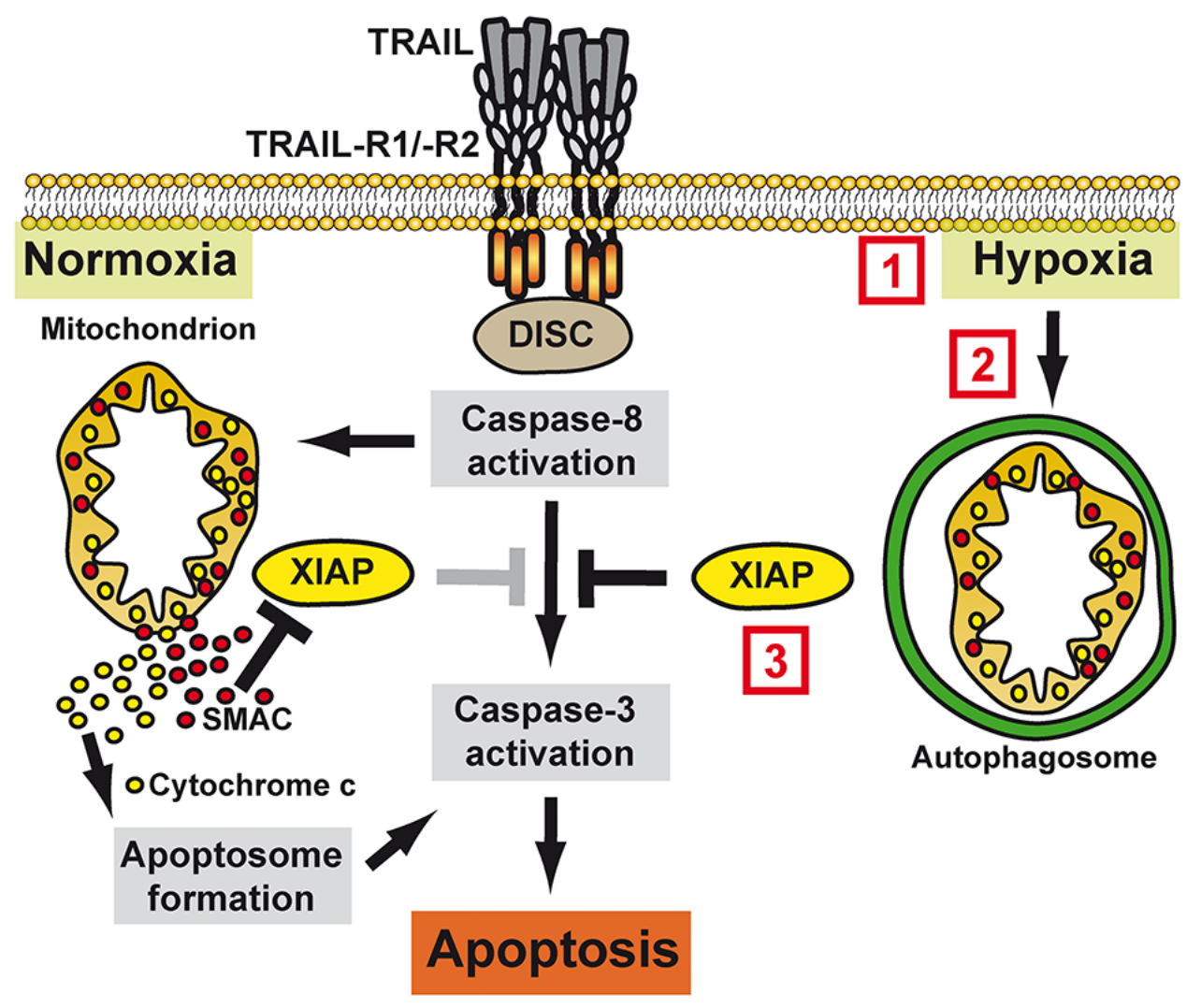

Figure 9: Molecular mechanism of hypoxia-induced TRAIL resistance in colorectal cancer cells. Under normoxic conditions, TRAIL-R1/-R2 activation triggers DISC assembly with subsequent caspase-8 activation. Mitochondria amplify the death signal via the release of pro-apoptotic factors such as cytochrome $\mathrm{c}$ and SMAC, which boost caspase-3 activation by initiating apoptosome formation and antagonizing XIAP, respectively. Under hypoxic conditions, mitophagy sequesters mitochondria-derived pro-apoptotic molecules, thereby blocking efficient apoptosis induction. Therapeutically, hypoxia-induced TRAIL resistance can be overcome by (1) increasing local oxygen levels (e.g. systemic hyperoxia or promoting angiogenesis), (2) inhibition of hypoxia-induced mitophagy (e.g. Bay87-2243 targeting HIF1 $\alpha$ or 3MA blocking autophagosome formation) or (3) targeting XIAP (e.g. SMAC mimetics or blocking XIAP transcription using MithA).

\section{MATERIALS AND METHODS}

\section{Cell lines, antibodies and reagents}

HCT116 and DLD1 cells were purchased from the German Collection of Microorganisms and Cell Culture (DSMZ, Braunschweig, Germany). HCT-8 cells were obtained from Cell Line Service GmbH (CLS, Eppelheim, Germany). Cell lines were authenticated by STR profiling. HCT116 $\mathrm{Bax}^{-/}$[45] and HCT116 $\mathrm{XIAP}^{-/-}$[46] cells were kindly provided by Bert Vogelstein (Johns Hopkins University, Baltimore, MA, USA) and Philipp Jost (III. Medizinische Klinik, Technische Universität München, Germany), respectively. Cells were cultured in RPMI 1640 medium (PAN Biotech, Aidenbach, Germany) supplemented with $10 \%[\mathrm{v} / \mathrm{v}]$ fetal calf serum (Sigma, Steinheim, Germany). Oxygen levels were modulated using a Whitley H35 Hypoxystation (Don Whitley Scientific, Shipley, UK). Antibodies specific for FADD, caspase-8, Bax and XIAP were purchased from Cell Signaling Technology (Beverly, MA, USA).
Anti-TRAIL-R1, anti-TRAIL-R2, anti-TRAIL-R3 and anti-TRAIL-R4 antibodies were from ProSci (Poway, CA, USA), anti-HIF1 $\alpha$ was from Cayman Chemical (Ann Arbor, MI, USA) and anti-tubulin from Dunnlab (Asbach, Germany). BV6, LCL161, Bay872243, staurosporine (STS), cis-platin (cisPt) and 3-methyladenine (3MA) were obtained from Selleck Chemicals (Houston, TX, USA). Mithramycin-A was from AppliChem (Darmstadt, Germany), zVADfmk from Bachem (Heidelberg, Germany) and MTT (3-[4,5-dimethylthiazol-2-yl]-2,5-diphenyltetrazolium bromide) from Biomol (Hamburg, Germany). Human recombinant TRAIL was purchased from Apronex (Jesenice u Prahy, Czech Republic) and CD95L was from Adipogen (Liestal, Switzerland). Fc-FLAGscTRAIL was generated by in-frame insertion of FLAG-scTRAIL [47] into a pCR3 variant encoding the IgG1 Fc domain and a linker (kind gift from $\mathrm{P}$. Schneider, Department of Biochemistry, University of Lausanne). Recombinant Fc-FLAG-TRAIL was produced in HEK293 cells as previously described for TL1A [48]. 


\section{Western blot analysis}

Western blot analysis were performed essentially as described previously [7]. Briefly, cells were harvested, spun down, and dissolved in $4 \mathrm{x}$ Laemmli sample buffer $(8 \%$ [w/v] SDS, $0.1 \mathrm{M}$ dithiothreitol, $40 \%$ [v/v] glycerol, 0.2 $\mathrm{M}$ Tris, $\mathrm{pH}$ 8.0) supplemented with phosphatase inhibitor cocktails-I and -II (Sigma). Samples were sonificated, subsequently boiled $\left(96^{\circ} \mathrm{C}, 5 \mathrm{~min}\right)$. Proteins were separated by SDS-PAGE and transferred to PVDF membranes. Incubation in TBS containing $0.1 \%(\mathrm{v} / \mathrm{v})$ Tween 20 and $5 \%(\mathrm{w} / \mathrm{v})$ dry milk blocked non-specific binding sites. Membranes were incubated with primary antibodies of the specificity of interest. Antigen-antibody complexes were visualized using horseradish peroxidase-conjugated secondary antibodies (Dako, Hamburg, Germany) and ECL technology (Pierce, Rockford, IL, USA). Mitochondria were isolated using the "Mitochondria Isolation Kit for Cultured Cells" (ThermoFisher Scientific, Waltham, MA, USA) following manufacturer's instructions.

\section{Coimmunoprecipitation}

Immunoprecipitation of Fc-FLAG-scTRAIL was essentially performed as described previously for CD95L [7]. In brief, four confluent $150 \mathrm{~cm}^{2}$ tissue culture dishes per condition were stimulated with $1 \mu \mathrm{g} / \mathrm{mL}$ Fc-FLAGscTRAIL for $90 \mathrm{~min}$ at $37^{\circ} \mathrm{C}$, washed in ice-cold TBS, transferred in $2 \mathrm{~mL}$ lysis buffer $(50 \mathrm{mM}$ Tris- $\mathrm{HCl}, \mathrm{pH}$ $7.5,150 \mathrm{mM} \mathrm{NaCl}, 0.5 \%$ [v/v] NP40) supplemented with complete protease inhibitor cocktail (Roche, Mannheim, Germany), and incubated for $60 \mathrm{~min}$ on ice. Lysates were cleared by centrifugation $(2 \times 20 \mathrm{~min}, 14.000 \mathrm{~g})$ and TRAIL-R1/-R2 complexes were precipitated using protein $\mathrm{G}$ agarose (Roche, $40 \mu \mathrm{L}$ of a $50 \%[\mathrm{v} / \mathrm{v}]$ slurry) at $4{ }^{\circ} \mathrm{C}$ overnight. Lysates from unstimulated cells supplemented with $50 \mathrm{ng} / \mathrm{mL}$ of Fc-FLAG-scTRAIL before adding protein $\mathrm{G}$ agarose served as negative control. After washing three times in TBS, agarosebound proteins were eluted by incubation at $95^{\circ} \mathrm{C}$ for 10 min in 2x Laemmli sample buffer.

\section{Cell viability assay}

Cells were seeded in 96 -well plates $\left(2 \times 10^{4}\right.$ per well) and grown in the presence of the indicated oxygen levels for $18 \mathrm{~h}$. Subsequently, cells were stimulated with the indicated concentrations of the ligands in triplicates. Cell viability was determined $18 \mathrm{~h}$ after stimulation using 3-[4,5-dimethylthiazol-2-yl]-2,5diphenyl tetrazolium bromide (MTT) or crystal violet staining.

\section{Flow cytometry}

Cells were grown under normoxic $\left(21 \% \mathrm{O}_{2}\right)$ or hypoxic $\left(0.5 \% \mathrm{O}_{2}\right)$ conditions for $18 \mathrm{~h}$, harvested, and incubated for 30 min on ice with PE-conjugated antibodies specific for the indicated TRAIL-receptors (Diaclone SAS, Besancon, France) or an appropriate isotype control (R\&D Systems). Analyses were performed using FACSCanto II (BD Biosciences, Heidelberg, Germany) following standard procedures.

\section{Caspase activity assay and phosphatidylserine measurements}

$3 \times 10^{4}$ cells per well were seeded in black 96well plates (clear bottom) and grown under normoxic $\left(21 \% \mathrm{O}_{2}\right)$ or hypoxic $\left(0.5 \% \mathrm{O}_{2}\right)$ conditions for $18 \mathrm{~h}$. Subsequently, cells were challenged with the indicated concentrations of TRAIL for $3 \mathrm{~h}$ (phosphatidylserine measurements), $4 \mathrm{~h}$ (caspase- 8 measurements) or $5 \mathrm{~h}$ (caspase-3 measurements). Translocation of phosphatidylserine to the outer leaflet of the plasma membrane was determined using a fluorogenic Annexin $\mathrm{V}$ derivate (Phosphatidylserine apoptosis assay, AAT Bioquest, Sunnyvale, CA, USA). Caspase activity was determined using the fluorogenic substrates (DEVD) -R110 (Caspase-3 activity kit, AAT Bioquest) or (Ac-IETD) $)_{2}$-R110 (Caspase-8 activity kit, AAT Bioquest) according to the manufacturer's instructions. Light emission was quantified using a Victor3 multilabel reader (Perkin Elmer, Waltham, MA, USA). All groups were analyzed in triplicates.

\section{Fluorescence-based measurements of mitochondrial mass}

DLD1 cells were seeded in black 96-well plates $\left(3 \times 10^{4}\right.$ cells/well $)$ with clear bottom and grown under normoxic or hypoxic conditions for $18 \mathrm{~h}$. Before staining, cells were washed once with $37^{\circ} \mathrm{C}$ warm Hank's buffered salt solution (HBSS, Sigma) and incubated with 200 nM MitoTracker Green FM (ThermoFisher Scientific) for $45 \mathrm{~min}$ at $37^{\circ} \mathrm{C}$ protected from light. Subsequently, staining solution was removed by aspiration, cells were again washed in HBSS and fluorescence intensity was measured using a Victor3 multilabel reader (Perkin Elmer, Waltham, MA, USA). All groups were analyzed in triplicates.

\section{Fluorescence-based autophagy assay}

Autophagosome formation was measured using the "Cell MeterTM Autophagy Fluorescence Imaging Kit" (AAT Bioquest) according to manufacturer's instructions. In brief, $3 \times 10^{4}$ cells per well cells were seeded in black 96-well plates and incubated for $18 \mathrm{~h}$ under normoxic or hypoxic conditions. Autophagosomes were stained after media removal by incubation for $1 \mathrm{~h}$ in PhagyGreen ${ }^{\mathrm{TM}}$ staining solution at $37^{\circ} \mathrm{C}$ protected from light. Subsequently, cells were washed three times and fluorescence intensity was measured using a Victor3 
multilabel reader (Perkin Elmer). All groups were analyzed in triplicates.

\section{Measurement of cytosolic $\mathrm{Ca}^{2+}$ levels}

Cytosolic $\mathrm{Ca}^{2+}$ levels were measured using the "Fluo-4 Direct Calcium Assay" (ThermoFisher Scientific). Cells were seeded in black 96 -well plates $\left(3 \times 10^{4}\right.$ per well) and incubated for $18 \mathrm{~h}$ under normoxic or hypoxic conditions. Subsequently, cells were challenged with TRAIL $(256 \mathrm{ng} / \mathrm{mL})$ for the indicated periods of time followed by direct addition of the Fluo-4-containing staining solution into the culture media. Fluorescence intensity was measured after $1 \mathrm{~h}$ incubation $\left(37^{\circ} \mathrm{C}\right.$, protected from light) using a Victor 3 multilabel reader (Perkin Elmer).

\section{Proteomic profiling}

Oxygen-dependent changes in the relative expression of pro- and anti-apoptotic proteins were analyzed in DLD1 cells grown under normoxic $(21 \%$ $\left.\mathrm{O}_{2}\right)$ or hypoxic $\left(0.5 \% \mathrm{O}_{2}\right)$ conditions for $18 \mathrm{~h}$ using the "Human Apoptosis Antibody Array Kit" (R\&D Systems, Wiesbaden, Germany) according to manufacturer's instructions. Intensity of the protein spots were quantified by densitometry using the open source software ImageJ $1.47 \mathrm{v}$ (Wayne Rasband; National Institutes of Health, Bethesda, MD, USA) and normalized to reference spots included in each panel.

\section{ACKNOWLEDGMENTS}

We thank Harald Wajant (Department of Molecular Internal Medicine, University Hospital Würzburg, Germany) for kindly providing the Fc-FLAG-scTRAIL plasmid. We also thank André Gessner for generous support.

\section{CONFLICTS OF INTEREST}

The authors declare no competing financial interests.

\section{GRANT SUPPORT}

$\mathrm{ME}$ and JJ are supported by grants from Deutsche Forschungsgemeinschaft (EH 465/2-1 and JA1993/2-1). ME is supported by grants from the Roggenbuck Stiftung, the Walter-Schulz-Stiftung and the Medical Faculty of the University of Regensburg (ReForM-B).

\section{Author contributions}

$\mathrm{ME}$, JJ and GK designed the experiments; ME, $\mathrm{SB}, \mathrm{MK}$, and GK performed the experiments, ME and JJ analyzed the data, ME wrote the paper.

\section{REFERENCES}

1. Walczak H, Miller RE, Ariail K, Gliniak B, Griffith TS, Kubin M, Chin W, Jones J, Woodward A, Le T, Smith C, Smolak P, Goodwin RG, et al. Tumoricidal activity of tumor necrosis factor-related apoptosis-inducing ligand in vivo. Nat Med. 1999; 5:157-163.

2. Schug ZT, Gonzalvez F, Houtkooper RH, Vaz FM and Gottlieb E. BID is cleaved by caspase- 8 within a native complex on the mitochondrial membrane. Cell Death Differ. 2011; 18:538-548.

3. Westphal D, Kluck RM and Dewson G. Building blocks of the apoptotic pore: how Bax and Bak are activated and oligomerize during apoptosis. Cell Death Differ. 2014; 21:196-205.

4. Deveraux QL and Reed JC. IAP family proteins-suppressors of apoptosis. Genes Dev. 1999; 13:239-252.

5. Suzuki Y, Imai Y, Nakayama H, Takahashi K, Takio K and Takahashi R. A serine protease, HtrA2, is released from the mitochondria and interacts with XIAP, inducing cell death. Mol Cell. 2001; 8:613-621.

6. Lemke J, von Karstedt S, Zinngrebe J and Walczak H. Getting TRAIL back on track for cancer therapy. Cell Death Differ. 2014; 21:1350-1364.

7. Ehrenschwender M, Siegmund D, Wicovsky A, Kracht M, Dittrich-Breiholz O, Spindler V, Waschke J, Kalthoff H, Trauzold A and Wajant H. Mutant PIK3CA licenses TRAIL and CD95L to induce non-apoptotic caspase-8-mediated ROCK activation. Cell Death Differ. 2010; 17:1435-1447.

8. Samuels Y, Diaz LA, Jr., Schmidt-Kittler O, Cummins JM, Delong L, Cheong I, Rago C, Huso DL, Lengauer C, Kinzler KW, Vogelstein B and Velculescu VE. Mutant PIK3CA promotes cell growth and invasion of human cancer cells. Cancer Cell. 2005; 7:561-573.

9. Hanahan D and Weinberg RA. Hallmarks of cancer: the next generation. Cell. 2011; 144:646-674.

10. Semenza GL. HIF-1 mediates metabolic responses to intratumoral hypoxia and oncogenic mutations. J Clin Invest. 2013; 123:3664-3671.

11. Nagaraju GP, Bramhachari PV, Raghu G and El-Rayes BF. Hypoxia inducible factor-1alpha: Its role in colorectal carcinogenesis and metastasis. Cancer Lett. 2015; 366:11-18.

12. Baba $\mathrm{Y}$, Nosho $\mathrm{K}$, Shima $\mathrm{K}$, Irahara N, Chan AT, Meyerhardt JA, Chung DC, Giovannucci EL, Fuchs CS and Ogino S. HIF1A overexpression is associated with poor prognosis in a cohort of 731 colorectal cancers. Am J Pathol. 2010; 176:2292-2301.

13. Carreau A, El Hafny-Rahbi B, Matejuk A, Grillon C and Kieda C. Why is the partial oxygen pressure of human tissues a crucial parameter? Small molecules and hypoxia. J Cell Mol Med. 2011; 15:1239-1253.

14. Schneider-Brachert W, Heigl U and Ehrenschwender M. Membrane trafficking of death receptors: implications on signalling. Int J Mol Sci. 2013; 14:14475-14503. 
15. Orrenius S, Gogvadze V and Zhivotovsky B. Calcium and mitochondria in the regulation of cell death. Biochem Biophys Res Commun. 2015; 460:72-81.

16. Wozniak AL, Wang X, Stieren ES, Scarbrough SG, Elferink CJ and Boehning D. Requirement of biphasic calcium release from the endoplasmic reticulum for Fas-mediated apoptosis. J Cell Biol. 2006; 175:709-714.

17. Urresti J, Ruiz-Meana M, Coccia E, Arevalo JC, Castellano J, Fernandez-Sanz C, Galenkamp KM, Planells-Ferrer L, Moubarak RS, Llecha-Cano N, Reix S, Garcia-Dorado D, Barneda-Zahonero B, et al. Lifeguard Inhibits Fas Ligandmediated Endoplasmic Reticulum-Calcium Release Mandatory for Apoptosis in Type II Apoptotic Cells. J Biol Chem. 2016; 291:1221-1234.

18. Zhang H, Bosch-Marce M, Shimoda LA, Tan YS, Baek JH, Wesley JB, Gonzalez FJ and Semenza GL. Mitochondrial autophagy is an HIF-1-dependent adaptive metabolic response to hypoxia. J Biol Chem. 2008; 283:10892-10903.

19. Ellinghaus P, Heisler I, Unterschemmann K, Haerter M, Beck H, Greschat S, Ehrmann A, Summer H, Flamme I, Oehme F, Thierauch K, Michels M, Hess-Stumpp H, et al. BAY 87-2243, a highly potent and selective inhibitor of hypoxia-induced gene activation has antitumor activities by inhibition of mitochondrial complex I. Cancer Med. 2013; 2:611-624.

20. Fulda S. Molecular pathways: targeting inhibitor of apoptosis proteins in cancer--from molecular mechanism to therapeutic application. Clin Cancer Res. 2014; 20:289-295.

21. Jost PJ, Grabow S, Gray D, McKenzie MD, Nachbur U, Huang DC, Bouillet P, Thomas HE, Borner C, Silke J, Strasser A and Kaufmann T. XIAP discriminates between type I and type II FAS-induced apoptosis. Nature. 2009; 460:1035-1039.

22. Hao Z and Mak TW. Type I and type II pathways of Fasmediated apoptosis are differentially controlled by XIAP. J Mol Cell Biol. 2010; 2:63-64.

23. Gillissen B, Richter A, Overkamp T, Essmann F, Hemmati PG, Preissner R, Belka C and Daniel PT. Targeted therapy of the XIAP/proteasome pathway overcomes TRAILresistance in carcinoma by switching apoptosis signaling to a Bax/Bak-independent 'type I' mode. Cell Death Dis. 2013; 4:e643.

24. Ehrenschwender M, Bittner S, Seibold K and Wajant H. XIAP-targeting drugs re-sensitize PIK3CA-mutated colorectal cancer cells for death receptor-induced apoptosis. Cell Death Dis. 2014; 5:e1570.

25. Lee TJ, Jung EM, Lee JT, Kim S, Park JW, Choi KS and Kwon TK. Mithramycin A sensitizes cancer cells to TRAIL-mediated apoptosis by down-regulation of XIAP gene promoter through Sp1 sites. Mol Cancer Ther. 2006; 5:2737-2746.

26. Weinmann M, Marini P, Jendrossek V, Betsch A, Goecke $\mathrm{B}$, Budach $\mathrm{W}$ and Belka C. Influence of hypoxia on
TRAIL-induced apoptosis in tumor cells. Int J Radiat Oncol Biol Phys. 2004; 58:386-396.

27. Mayes PA, Campbell L, Ricci MS, Plastaras JP, Dicker DT and El-Deiry WS. Modulation of TRAIL-induced tumor cell apoptosis in a hypoxic environment. Cancer Biol Ther. 2005; 4:1068-1074.

28. Kim M, Park SY, Pai HS, Kim TH, Billiar TR and Seol DW. Hypoxia inhibits tumor necrosis factor-related apoptosis-inducing ligand-induced apoptosis by blocking Bax translocation. Cancer Res. 2004; 64:4078-4081.

29. Park JY, Jeong JK, Lee JH, Moon JH, Kim SW, Lee YJ and Park SY. Induction of cellular prion protein (PrPc) under hypoxia inhibits apoptosis caused by TRAIL treatment. Oncotarget. 2015; 6:5342-5353. doi: 10.18632/oncotarget.3028.

30. Kim SW and Park SY. Hypoxia-mediated activation of autophagic flux inhibits apoptosis of keratinocytes via blocking tumor necrosis factorrelated apoptosisinducing ligand. Mol Med Rep. 2016; 13:805-810.

31. Han SH, Kim M, Park K, Kim TH and Seol DW. Blockade of processing/activation of caspase- 3 by hypoxia. Biochem Biophys Res Commun. 2008; 375:684-688.

32. Liu L, Feng D, Chen G, Chen M, Zheng Q, Song P, Ma Q, Zhu C, Wang R, Qi W, Huang L, Xue P, Li B, et al. Mitochondrial outer-membrane protein FUNDC1 mediates hypoxia-induced mitophagy in mammalian cells. Nat Cell Biol. 2012; 14:177-185.

33. Han J, Hou W, Goldstein LA, Lu C, Stolz DB, Yin XM and Rabinowich $\mathrm{H}$. Involvement of protective autophagy in TRAIL resistance of apoptosis-defective tumor cells. J Biol Chem. 2008; 283:19665-19677.

34. Hou W, Han J, Lu C, Goldstein LA and Rabinowich H. Enhancement of tumor-TRAIL susceptibility by modulation of autophagy. Autophagy. 2008; 4:940-943.

35. Azijli K, Weyhenmeyer B, Peters GJ, de Jong S and Kruyt FA. Non-canonical kinase signaling by the death ligand TRAIL in cancer cells: discord in the death receptor family. Cell Death Differ. 2013; 20:858-868.

36. Brint E, $\mathrm{O}^{\circ} \mathrm{Callaghan} \mathrm{G}$ and Houston A. Life in the Fas lane: differential outcomes of Fas signaling. Cell Mol Life Sci. 2013; 70:4085-4099.

37. Nijkamp MW, Hoogwater FJ, Steller EJ, Westendorp BF, van der Meulen TA, Leenders MW, Borel Rinkes IH and Kranenburg O. CD95 is a key mediator of invasion and accelerated outgrowth of mouse colorectal liver metastases following radiofrequency ablation. J Hepatol. 2010; 53:1069-1077.

38. Hatfield SM, Kjaergaard J, Lukashev D, Belikoff B, Schreiber TH, Sethumadhavan S, Abbott R, Philbrook P, Thayer M, Shujia D, Rodig S, Kutok JL, Ren J, et al. Systemic oxygenation weakens the hypoxia and hypoxia inducible factor 1alpha-dependent and extracellular adenosine-mediated tumor protection. J Mol Med (Berl). 2014; 92:1283-1292. 
39. Hatfield SM, Kjaergaard J, Lukashev D, Schreiber TH, Belikoff B, Abbott R, Sethumadhavan S, Philbrook P, Ko K, Cannici R, Thayer M, Rodig S, Kutok JL, et al. Immunological mechanisms of the antitumor effects of supplemental oxygenation. Sci Transl Med. 2015; 7:277ra230.

40. Wong PP, Demircioglu F, Ghazaly E, Alrawashdeh W, Stratford MR, Scudamore CL, Cereser B, CrnogoracJurcevic T, McDonald S, Elia G, Hagemann T, Kocher HM and Hodivala-Dilke KM. Dual-action combination therapy enhances angiogenesis while reducing tumor growth and spread. Cancer Cell. 2015; 27:123-137.

41. Varfolomeev E, Blankenship JW, Wayson SM, Fedorova AV, Kayagaki N, Garg P, Zobel K, Dynek JN, Elliott LO, Wallweber HJ, Flygare JA, Fairbrother WJ, Deshayes K, et al. IAP antagonists induce autoubiquitination of c-IAPs, NF-kappaB activation, and TNFalpha-dependent apoptosis. Cell. 2007; 131:669-681.

42. Eckelman BP, Salvesen GS and Scott FL. Human inhibitor of apoptosis proteins: why XIAP is the black sheep of the family. EMBO Rep. 2006; 7:988-994.

43. Jouan-Lanhouet S, Arshad MI, Piquet-Pellorce C, Martin-Chouly C, Le Moigne-Muller G, Van Herreweghe F, Takahashi N, Sergent O, Lagadic-Gossmann D, Vandenabeele P, Samson M and Dimanche-Boitrel MT.
TRAIL induces necroptosis involving RIPK1/RIPK3dependent PARP-1 activation. Cell Death Differ. 2012; 19:2003-2014.

44. Vanden Berghe T, Linkermann A, Jouan-Lanhouet S, Walczak H and Vandenabeele P. Regulated necrosis: the expanding network of non-apoptotic cell death pathways. Nat Rev Mol Cell Biol. 2014; 15:135-147.

45. Zhang L, Yu J, Park BH, Kinzler KW and Vogelstein B. Role of BAX in the apoptotic response to anticancer agents. Science. 2000; 290:989-992.

46. Cummins JM, Kohli M, Rago C, Kinzler KW, Vogelstein $\mathrm{B}$ and Bunz F. X-linked inhibitor of apoptosis protein (XIAP) is a nonredundant modulator of tumor necrosis factor-related apoptosis-inducing ligand (TRAIL)-mediated apoptosis in human cancer cells. Cancer Res. 2004; 64:3006-3008.

47. Schneider B, Munkel S, Krippner-Heidenreich A, Grunwald I, Wels WS, Wajant H, Pfizenmaier K and Gerspach J. Potent antitumoral activity of TRAIL through generation of tumor-targeted single-chain fusion proteins. Cell Death Dis. 2010; 1:e68.

48. Bittner S, Knoll G, Fullsack S, Kurz M, Wajant H and Ehrenschwender M. Soluble TL1A is sufficient for activation of death receptor 3. FEBS J. 2016; 283:323-336. 